\title{
Muon Tomography sites for Colombian volcanoes
}

\author{
Alejandra Vesga-Ramírez ${ }^{1}$, David Sierra-Porta*,2, Jésus Peña-Rodríguez ${ }^{3}$, \\ José David Sanabria-Gómez ${ }^{3}$, Martha Valencia-Otero ${ }^{3}$, Christian Sarmiento-Cano ${ }^{4}$, \\ Mauricio Suárez-Durán ${ }^{5}$, Hernán Asorey ${ }^{6}$, Luis A. Núñez ${ }^{7}$ \\ (1) Centro Internacional para Estudios de la Tierra, Comisión Nacional de Energía Atómica Buenos Aires-Argentina \\ (2) Departamento de Física, Universidad de los Andes, Cra. 1 No. 18A-10 Edificio Ip, CP 111711, Bogotá, Colombia \\ (3) Escuela de Física, Universidad Industrial de Santander, Bucaramanga-Colombia \\ (4) Instituto de Tecnologías en Detección y Astropartículas, 1650, Buenos Aires-Argentina \\ (5) Departamento de Física y Geología, Universidad de Pamplona, Pamplona-Colombia \\ (6) Laboratorio Detección de Partículas y Radiación, Instituto Balseiro. Centro Atómico Bariloche, Comisión Nacional de \\ Energía Atómica, Bariloche-Argentina;Universidad Nacional de Río Negro, 8400, Bariloche-Argentina and Instituto \\ de Tecnologías en Detección y Astropartículas, 1650, Buenos Aires-Argentina \\ (7) Escuela de Física, Universidad Industrial de Santander, Bucaramanga-Colombia and Departamento de Física, \\ Universidad de Los Andes, Mérida-Venezuela
}

Article history: received October 23, 2019; accepted January 2, 2020

\begin{abstract}
By using a very detailed simulation scheme, we have calculated the cosmic ray background flux at 13 active Colombian volcanoes and developed a methodology to identify the most convenient places for a muon telescope to study their inner structure. Our simulation scheme considers three critical factors with different spatial and time scales: the geo-magnetic effects, the development of extensive air showers in the atmosphere, and the detector response at ground level. The muon energy dissipation along the path crossing the geological structure is modeled considering the losses due to ionization, and also contributions from radiative Bremßtrahlung, nuclear interactions, and pair production. By examining each particular volcano topography and assuming reasonable statistics for different instrument acceptances, we obtained the muon flux crossing each structure and estimated the exposure time for our hybrid muon telescope at several points around each geological edifice. After a detailed study from the topography, we have identified the best volcano to be studied, spotted the best points to place a muon telescope and estimated its time exposures for a significant statistics of muon flux. We have devised a mix of technical and logistic rules -the "rule of thumb" criteria- and found that only Cerro Machín, located at the Cordillera Central $\left(4^{\circ} 29^{\prime} \mathrm{N} 75^{\circ} 22^{\prime} \mathrm{W}\right)$, can be feasibly studied today through muography. Cerro Negro and Chiles could be good candidates shortly.
\end{abstract}

Keywords: Muography; Muon; Volcanoes; Cosmic Ray Techniques; Background Rejection. 


\section{Alejandra Vesga-Ramírez et al.}

\section{Introduction}

Muography is a non-invasive astroparticle technique, introduced several decades ago for imaging anthropic and geologic structures, benefiting from the high penetration atmospheric muons produced in cosmic rays showers. This method offers a spatial resolution in the order of tens of meters, up to a kilometer of penetration, and measures the out-coming muon flux for different directions by means of a hodoscope. The flux variance between trajectories allows us to extract information about the inner density distribution of the scanned object.

In the beginning, the study of cosmic rays -and particularly their detection after crossing geological structures- were motivated by the need to understand the background noise in particle detectors inside anthropic/natural structures [George, 1955; Zichichi et al., 2000]. Luis Álvarez [Alvarez et al., 1970] was the first to apply muon radiography, with no results, to the pyramid of Cheops; but this initiative led to the successful Scan Pyramids project, which recently discovered cavities in the Pyramid of Khufu (Cheops) [Morishima et al., 2017].

The interest in muon radiography for Earth sciences studies arose after the discovery of the significant penetrating power of some high energy secondary particles produced by the interaction of cosmic rays with the atmosphere (hereafter, primaries). These particles can cross hundreds of meters of rock with an attenuation related to the amount of matter traversed along its trajectory [Nagamine, 2003]. This technique uses the same basic principles as a standard medical radiography: it measures, with a sensitive device, the attenuation of cosmic muons when crossing geological structures. Although there are limitations with muography in detecting deep structures beneath the volcano (such as a magma chamber), it is particularly useful when it is applied to shallow volcano phenomena such as the conduit dynamics. Thus, volcano muography constitutes an unique method to obtain direct information on the density distribution inside geological objects with a better spatial resolution than other geophysical techniques (see [Tanaka et al., 2007; Lesparre et al., 2010; Marteau et al., 2012; Okubo and Tanaka, 2012; Cârloganu et al., 2013; Portal et al., 2013; Jourde et al. 2013; Tanaka, 2013; Carbone et al., 2014; Tanaka, 2016; Thompson et al., 2020; Kaiser, 2019; Tanaka and Oláh, 2019, and references therein]).

Colombia, located in the Pacific Belt, has more than a dozen active volcanoes (see figure 1) clustered in three main groups along the Cordillera Central, the highest of the three branches of the Colombian Andes. Most of these volcanoes represent a significant risk to the nearby population in towns and/or cities [Cortés, 2016; Agudelo, 2016; Muñoz, 2017] and have caused major disasters. The most recent, the Armero tragedy occurred in November 13, 1985, when pyroclastics of the Nevado del Ruiz fused about $10 \%$ of the mountain glacier, sending lahars with the terrible, devastating result of 20,000 casualties [Pierson et al., 1990].

Therefore, to determine and to model the inner volcano structure is crucial in evaluating its potential risks. Muon tomography is a powerful technique, which measures the cosmic muon flux attenuation by rock volumes of different densities, allowing the projection of images of volcanic conduits at the top of the volcanic edifice. It constitutes an attractive way to infer density distributions inside different geological structures, which is critical in the study of possible eruption dynamics associated with specific eruptive styles. Nowadays, astroparticle research groups in Colombia have started to explore this technique to estimate the density distribution within geological edifices by recording the variation of the atmospheric muon flux crossing the structure [Tapia et al., 2016; Asorey et al., 2018a, 2018b; Peña-Rodríguez et al., 2019; Guerrero et al., 2019; Torres et al., 2019; UsecheParra and Avila-Bernal, 2019].

The objective of the present work is twofold: first, to identify possible muon telescope observation sites to study Colombian active volcanoes by estimating the muon flux emerging from the geological edifices and second, to determine the time exposure for our hybrid muon telescope at those selected sites. Section 2 describes four of the main active Colombian volcanoes. In Section 3, we discuss the detailed simulation scheme used to estimate the incoming atmospheric muon flux and, we also investigate the energy loss of muons crossing the volcano edifice. For completeness, our hybrid muon telescope is briefly described in section 4. In 5, we analyze muon propagation across the Machín volcano and calculate the exposure times for four observation points. We also estimate the outgoing muon flux from the geological structures that could be detected by our telescope. Besides, this Section discusses a ray-tracing analysis for muon propagation at three other active volcanoes: Chiles, Cerro Negro, and Galeras. From the previous results we devise in Section 6 "rule of thumb" criteria that should be fulfilled by the potential sites and apply them to 13 active Colombian volcanoes. Finally, in Section 7 conclusions are presented along with possible future works. 


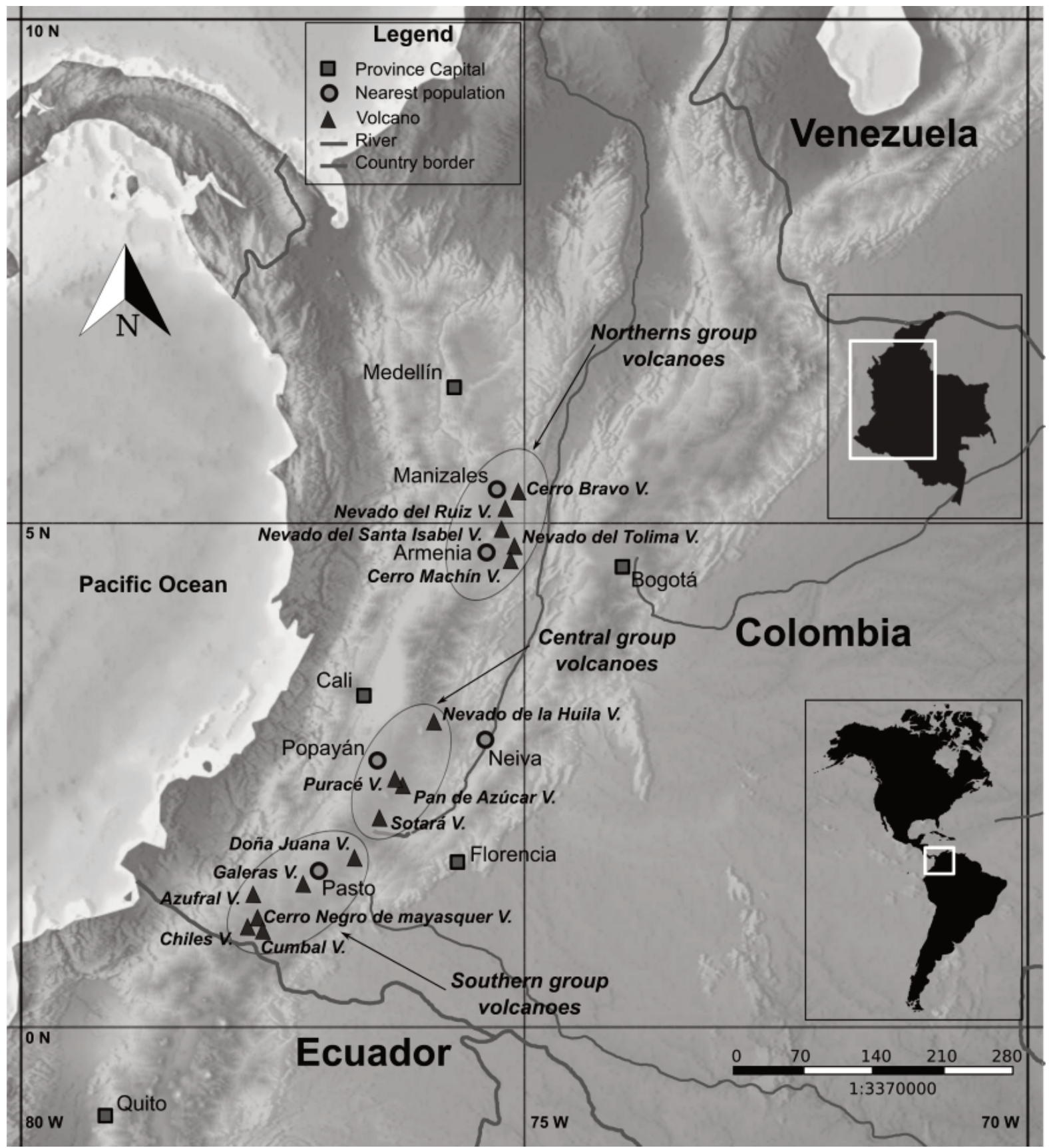

Figure 1. Artistic representation of 13 Colombian active volcanoes -Azufral, Cerro Negro, Chiles, Cumbal, Doña Juana, Galeras, Machín, Nevado del Huila, Nevado del Ruíz, Nevado Santa Isabel, Nevado del Tolima, Puracé, and Sotaráare displayed in three disperse clusters through the Cordillera Central. Because of their social significance and eruptive history, we shall briefly focus on four of them: Galeras, Nevado del Ruiz, Cerro Machín and Cerro NegroChiles. Galeras, Cerro Negro-Chiles volcanoes are found in the southern cluster, while Nevado del Ruiz and Cerro Machín are located within the most northern one. 


\section{Alejandra Vesga-Ramírez et al.}

\section{Volcanoes in Colombia}

In this work, we have considered 13 Colombian active volcanoes: Azufral, Cerro Negro, Chiles, Cumbal, Doña Juana, Galeras, Machín, Nevado del Huila, Nevado del Ruíz, Nevado Santa Isabel, Nevado del Tolima, Puracé, and Sotará. Figure 1 displays an artistic representation of their geographic distribution. Because of their social significance and eruptive history, we shall briefly describe some of the characteristics of four of them: Galeras, Nevado del Ruiz, Cerro Machín, and the Cerro Negro-Chiles complex.

\subsection{Cerro Machín}

The Machín volcano is often overlooked as a minor edifice in the Cerro Bravo-Cerro Machín volcanic belt but, considering its high explosive potential, dacitic composition and magnitude of past eruptions, it must be considered one of the most dangerous active volcanoes in Colombia [Cortés, 2001]. It is also located at the Cordillera Central $\left(4^{\circ} 29^{\prime} \mathrm{N} 75^{\circ} 22^{\prime} \mathrm{W}\right)$, between Cajamarca and Machín [Cepeda et al., 1995].

Over the last 5,000 years, Machín has had six eruptions -the last one occurred about 850 years ago-generating pyroclastic flows, depositing several tens of centimeters of ash layers, throwing eruptive columns (several tens of kilometers) and flows of volcanic mud. In recent times, some of the manifestations of Machín's volcanic activity are the presence of fumaroles, permanent micro-seismicity, thermal waters flowing in the vicinity of the crater, geoforms of the well-preserved volcanic building and a more significant presence of Radon gas in the sector [Cortés, 2001; Rueda, 2005].

The Machín volcano, with a crater $2.4 \mathrm{~km}$ diameter and $450 \mathrm{~m}$ high, polygenetic, has a dome -developed through hundreds of thousands or million years-, with sedimentary and morphologic characteristics that suggest a Toba cone structure, built during the most recent phreatomagmatic [Aguilar Casalla et al., 2017]. According to studies related to the geological history of this volcano, a future pyroclastic eruptive episode would be deposited mainly in an area of $10 \mathrm{~km}^{2}$ around the volcano edifice [Murcia et al. 2010]. The similarity in the morphology of two volcanic structures and the activity of one of them must be taken into account, as one more element, in the evaluation of the danger of an eventual eruption. That could be the case with the similitude of the Cerro Machín Volcano and the Chichón or Chichonal Volcano in southern México in the state of Chiapas $\left(17^{\circ} 21^{\prime} \mathrm{N} 93^{\circ} 41^{\prime} \mathrm{W} ; 1100\right.$ m.a.s.l, https://en.wikipedia.org/wiki/Chichonal) which should alert about the potential danger of Machín volcano.

\subsection{Cerro Negro - Chiles}

The Chiles and Cerro Negro are located on the Colombia-Ecuador border, $86 \mathrm{~km}$ from the city of San Juan de Pasto, at geographic coordinates $0^{\circ} 49^{\prime} \mathrm{N} 77^{\circ} 56^{\prime} \mathrm{W}$ and $0^{\circ} 46^{\prime} \mathrm{N} 77^{\circ} 57^{\prime} \mathrm{W}$, respectively.

This volcanic complex lies at the intersections of three faults: Chiles-Cerro Negro, Chiles-Cumbal and Cerro Negro-Nasta. The volcanic domes reach 4748 m.a.s.l (Chiles), 4470 m.a.s.l (Cerro Negro), and their craters have diameters of $1.0 \mathrm{~km}$ and $1.8 \mathrm{~km}$, respectively. These two adjacent volcanic cones are collapsed towards the north (Chiles) and west (Cerro Negro), with the presence of geoforms of an already extinct glacier action. Their buildings are formed mainly by several episodes of lava and pyroclastic, with main volcanic products classified as andesites of two pyroxenes and olivines. Although there are no historical records of eruptive activity, there is evidence of highly explosive stages, and the current activity is displayed by the presence of hot springs and solfataras. On the Ecuadorian side of Chiles, there is a seismological station which detects various activity.

\subsection{Galeras}

The Galeras volcanic complex -located in southwest Colombia: $1^{\circ} 13^{\prime} 18.58^{\prime \prime} \mathrm{N}, 7^{\circ} 21^{\prime} 33.86^{\prime \prime} \mathrm{W}$ - is the most active volcano in Colombia with the highest social risk due to its regular activity and the populated area that surrounds it.

Surpassing 5,000 years of antiquity, this volcanic complex has a base diameter of $20 \mathrm{~km}$, a summit elevation of 4,276 m.a.s.l., and a primary crater diameter of $320 \mathrm{~m}$. The active cone, called Galeras Volcano, rises $1600 \mathrm{~m}$ above 
and approximately $9 \mathrm{~km}$ away from the city of San Juan de Pasto (capital of Nariño department) with a population of 313,000 inhabitants. Galeras is characterized by andesite lava and pyroclastic with significant fallout deposits, displaying aconical shape with a large caldera at the top. After a long period of inactivity of more than 40 years, it awoke again in 1987, experimenting mainly minor eruptions, some with explosive character: fumarolic formation and enlargement, strong tremors, shockwaves and emission of pyroclasts and ashes [Calvache et al., 1997; Cruz and Chouet, 1997].

Since 2009, the activity has been considerably reduced to the expulsion of ashes -columns that have reached 10 km- and shockwaves [Cortés and Raigosa, 1997].

\subsection{Nevado del Ruíz}

The ice-covered volcano Nevado del Ruíz, found at the Cordillera Central $-4^{\circ} 53^{\prime} \mathrm{N}$ and $75^{\circ} 19^{\prime} \mathrm{W}$ - has an altitude of approximately 5390 m.a.s.l., covering an area of more than 200 square kilometers. Its main crater (Arenas) is one kilometer diameter and $240 \mathrm{~m}$ deep. La Piraña and La Olleta are two small parasitic edifices, and there are four Ushaped amphitheaters produced by flank collapse and fault activity [Sennert, 2016].

This enormous volcano is located at the junction of two fault systems: the $\mathrm{N}^{\circ} 5^{\circ} \mathrm{W}$ normal Villa María-Termales fault system and the $\mathrm{N} 20^{\circ} \mathrm{E}$ right-lateral strike-slip Palestina fault system [Borrero et al., 2009]. The north and northwest borders show uneven geometries caused by the location of large amphitheaters on the upper part of the volcano, the southern and southwestern fringes are marked by sharp regular slopes while the east and southeastern fringes present moderate-to-strong declivities and a significant thickness of glacier deposits.

The eruptive history of the Nevado del Ruíz runs from the Pleistocene to the present, and its stratigraphy has three main stages related to the alternate construction-destruction of its edifice: Ancestral Ruiz (2-1 mega-years), Older Ruiz (0.8-0.2 mega-years) and Present Ruiz ( $<0.15$ mega-years) [Thouret et al., 1990]. The present emplacement of lava domes is made of andesite and dacite inside older calderas [Huggel et al., 2007]. During the past 11,000 years, this volcano has passed through at least 12 eruption stages, which included multiple slope failures (rock avalanches), pyroclastic and lahars, leading to the partial destruction of the summit domes [Thouret et al., 1990; Huggel et al., 2007]. The eruptions of the last thousand years have mostly been small, excluding some like the phreatic-magmatic eruption on November 13, 1985, which involved the partial melting of the glacier cap and consequent lahars, which reached and destroyed the municipality of Armero-Tolima and caused a large number of casualties.

\section{Muon flux simulation chain and rock opacity}

\subsection{Muon flux simulation chain}

Particles measured at the ground level (secondaries from now on) come from a chain of interactions and reactions, started by the primaries impinging upon the outer atmosphere. The modulation of secondaries needs to be monitored and carefully corrected by taking into account atmospheric factors that could modify its flux. Thus, a complete and detailed simulation chain -considering factors such as geomagnetic conditions, atmospheric reaction and detector response- is needed to characterize the expected flux at the detector level. Any attempt to estimate the expected flux of secondaries at the detector level should consider a detailed simulation that takes into account all possible sources of flux variations of processes occurring at different spatial and time scales. We can illustrate this conceptual scheme as [Asorey et al., 2015; Suárez-Durán, 2015; Asorey et al., 2018]:

Cosmic Ray Flux $\rightarrow$ Heliosphere Modulated Flux $\rightarrow$ Magnetosphere $\rightarrow$ $\ldots \rightarrow$ Primaries $\rightarrow$ Atmosphere Secondaries $\rightarrow$ Detector response $\rightarrow$ Signals.

We start our simulation chain by characterizing the effects of the geomagnetic field on the propagation of charged particles contributing to the background radiation at ground level. This is included through the calculation of directional rigidity cut-off, $R_{c}$, at the detector site, determined by using the MAGNETOCosmics code, which 


\section{Alejandra Vesga-Ramírez et al.}

implements the backtracking technique [Desorgher, 2003; Masías-Meza and Dasso, 2014]. Geomagnetic field at any point of Earth is calculated by using the International Geomagnetic Field Reference [Finlay et al., 2010], for modeling the near-Earth magnetic field $\left(r<5 \mathrm{R}_{\oplus}\right)$ and by the Tsyganenko Magnetic Field model version 2001 to describe the outer field $\left(\mathrm{r}>>5 \mathrm{R}_{\oplus}\right)$ [Tsyganenko, 2002].

The second link in this chain corresponds to a detailed simulation of extensive air showers produced during the interaction of the flux of primaries -from protons to irons, i.e., $1 \leq \mathrm{Z} \leq 26$ - through the atmosphere. To obtain this very comprehensive secondary flux at ground level we use the CoRsiKA code [Heck et al., 1998], with a specially tuned set of simulation parameters adapted to a particular geographical site. We will display these parameters in Section 5.1 for the particular case of the Machín volcano. For the hadronic model of interaction in the distribution of secondaries at the level of the detector, we use QGSJET-II-04 [Ostapchenko, 2011] as a model, and for low energies, we choose the default option, GHEISHA-2002 [Fesefeldt, 1985].

To identify possible muon observation sites in Colombia, we shall implement the previously described calculation scheme only at secular geomagnetic conditions -i.e., static geomagnetic corrections- focusing on the detailed calculation of the crossing muon flux and the stopping power of the volcano edifice at different volcano sites. Although we have implemented this general scheme, we found that geo-magnetic corrections seem not to be significant for the geographical location of Colombian volcanoes, because it mainly affects low energy primaries [Asorey et al., 2018].

Finally, the detector response to the different types of secondary particles at ground level is simulated using a GEANT4 model [Agostinelli et al., 2003; Calderón-Ardila et al., 2015] for both the scintillator panels and the water Cherenkov detector, but this last step of the simulation chain will not be considered here but will be detailed in a coming work [Jaimes-Motta, 2018; Vásquez-Ramírez, 2019; Vásquez-Ramírez et al., 2020; J. Peña-Rodríguez et al., 2020].

\subsection{Directional muon rock opacity}

The open sky flux estimations at the ground level, influenced by various environmental parameters-altitude, geomagnetic corrections, solar modulation, and atmospheric variations- induce some critical features in the instrument design.

A comparison of the open sky particle flux $\Phi_{\text {os }}$ with the flux, $\Phi$, emerging after crossing the target provides information about its density gradient. To estimate this target density gradient, we define the directional rock opacity as the mass density $\rho$ integrated along the muon path $L$ as

$$
\varrho(L)=\int_{L} \rho(\xi) d \xi=\bar{\rho} \times L,
$$

where $\xi$ is a characteristic longitudinal coordinate through the volcano, $L$ is the total distance traveled by muons in the rock, $\bar{\rho}$ is the average density within the volcano. In our approach, we are assuming that the trajectories of muons are straight lines which are not affected by Coulomb scattering processes; therefore density distributions within volcano edifices can be inferred from the variation of its flux, $\Delta=\Phi-\Phi_{\text {os }}$. A more detailed calculation, including second-order effects, is being carried out and will be included in future characterizations of the selected places.

The muon energy loss along each path can be modeled as

$$
-\frac{d E}{d \varrho}=a(E)+b(E) E,
$$

for each muon arrival direction considering a uniform density distribution. Here $E$ is the muon energy; $a(E)$ and $b(E)$ are functional parameters depending on the rock composition/properties and $\varrho(L)$ is the density integrated along the trajectory of the muons (the opacity defined by eq. (1)). The coefficient $a(E)$ represents the energy loss due to ionization, while $b(E)$ takes into account the contribution of radiative losses, mainly Bremßtrahlung, nuclear interactions, and pair production. The main parameters to estimate the coefficients $a(E)$ and $b(E)$ are the average ratio $<\mathrm{Z} / \mathrm{A}>$ between the atomic and mass numbers of the material [Olive et al., 2014; Valencia-Otero, 2017; VesgaRamírez, 2018]. 


\section{MuTe: Colombian Muon Telescope}

There are three main types of detectors implemented for volcano muography: (a) nuclear emulsion detectors, (b) scintillation detectors, and (c) gaseous detectors. Each one has its pros and contras described in [Tanaka, 2016; Tanaka and Oláh, 2019]. The main issue in muography of large-size objects is the flux over estimation due to the background sources such as the soft component of Extended Air Showers [Nishiyama et al., 2014; Oláh and Varga, 2017] and upward-going muons [Jourde, 2013]. Here, we shall present a new hybrid Muon Telescope (MuTe), combining the facilities of a hodoscope with a water Cherenkov detector (WCD) to solve that drawback. The hodoscope estimates the event flux per trajectory depending on the fired pixels in the front and the rear panel. A Time-of-Flight, system measures the time taken by the crossing particles subtracting the nano-scale time stamp recorded in both panels. The WCD senses the Cherenkov photons generated in the water due to the interacting charged particle. The recorded photon yield is equivalent for the energy loss.

\subsection{General description}

Just for completeness, we briefly describe here the MuTe, its acceptance and noise reduction capabilities, later we employ these characteristics to estimate the time exposure of the instrument at the observational sites. A detailed description of the instrument capabilities is discussed elsewhere [Vásquez-Ramírez et al., 2020; PeñaRodríguez et al., 2020].

Figure 2 illustrates MuTe design which combines two detection techniques: a hodoscope formed by two detection planes of plastic scintillator bars, and a WCD, in an innovative setup which differentiates it from some previous detectors.

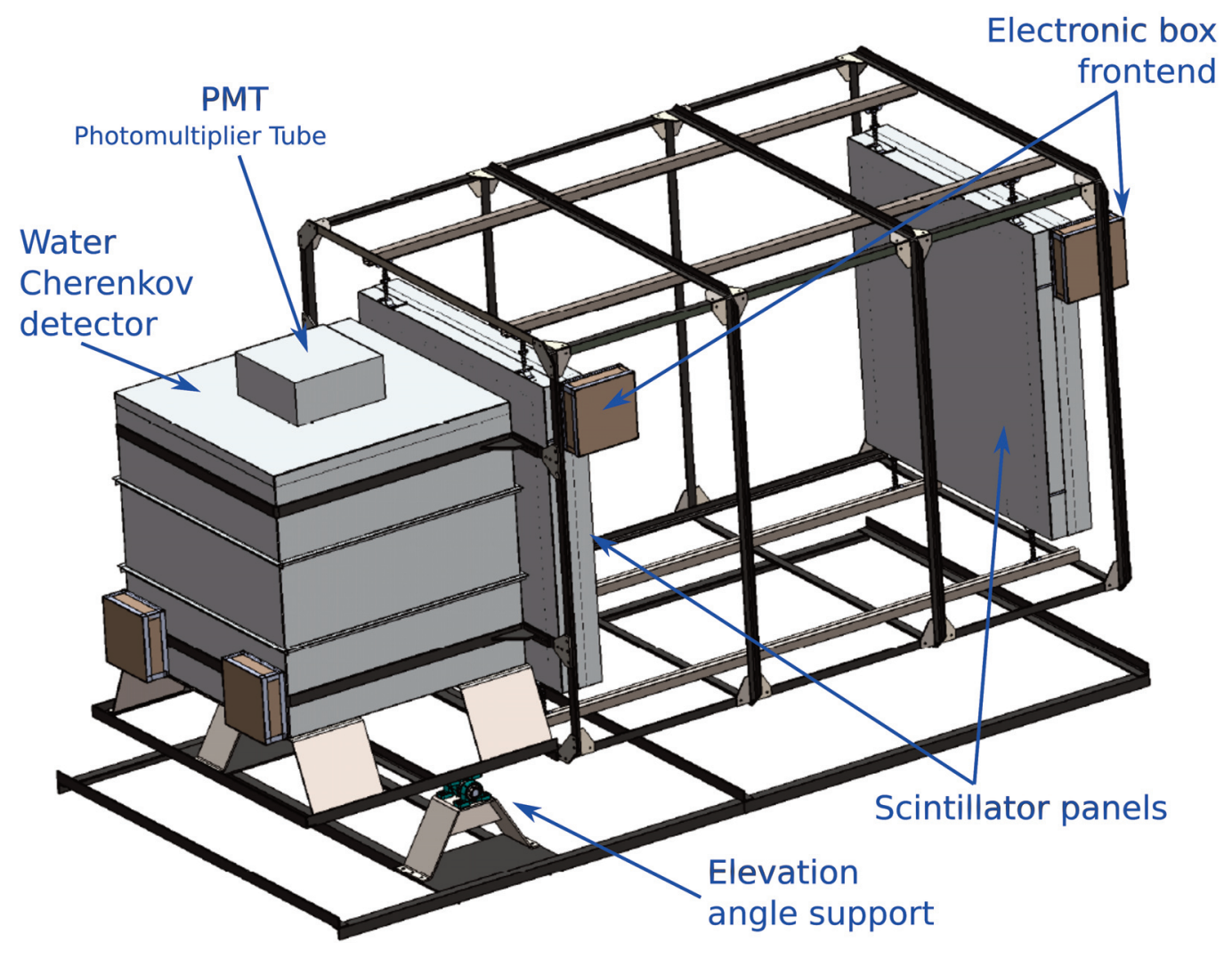

Figure 2. A sketch of our Colombian Muon Telescope (MuTe), which combines the facilities of a two-panel-hodoscope (900 pixels) and a $1.73 \mathrm{~m}^{3}$ water Cherenkov detector. 


\section{Alejandra Vesga-Ramírez et al.}

The features of the two subdetectors merged in MuTe are:

- Two-panel-hodoscope: Hodoscopes are the most common detectors designed and implemented for volcano muography. They consist of two or more panels devised to identify muon trajectories. Projects like ToMuVol [Cârloganu et al., 2013], DIAPHANE [Lesparre et al., 2010] and MU-RAY [Anastasio et al, 2013], use hodoscopes based on different detection technologies: emulsion plates, resistive plate chambers, micromegas, multi-wire proportional cameras, and scintillators, just to mention the most common ones. Inspired by the experiences of other volcano muography experiments [Uchida et al., 2009; Gibert et al., 2010], we have designed two X-Y arrays of $30 \times 30$ plastic scintillating strips $(120 \mathrm{~cm} \times 4 \mathrm{~cm} \times 1 \mathrm{~cm})$, made with StyronTM665-W polystyrene doped with a mixture of liquid organic scintillators: $1 \%$ of 2,5-diphenyloxazole (PPO) and 0.03\% of 1,4-bis (5phenyloxazol-2-yl) benzene (POPOP). Each array has 900 pixels of $4 \mathrm{~cm} \times 4 \mathrm{~cm}=16 \mathrm{~cm}^{2}$, which sums up 14,400 $\mathrm{cm}^{2}$ of detection surface which can be separated up to $D=250 \mathrm{~cm}$.

- Water Cherenkov Detector: The WCD indirectly detects charged secondaries, by the Cerenkov photons generated by relativistic particles traveling through the contained water. The photo-multiplier tube counts photo-electrons according to its quantum efficiency, which depends on the wavelength of the impacting photon. The MuTe WCD is a purified water cube of $120 \mathrm{~cm}$ side, located behind the rear scintillator panel (again, see figure 2), which acts as a calorimeter and as a third active coincidence detector.

\subsection{Telescope noise reduction capabilities}

The Colombian MuTe combines instrumentation and particle identification techniques to discriminate electron/positron from muon events, to filter soft muon impacts $(<1 \mathrm{GeV} / \mathrm{c})$ and also to reduce the noise from backward impinging particles. (see illustrations in figure 3). The Coulomb scattering noise, can be corrected offline. The MuTe implemented noise reduction are:

- Particle discrimination: Particle deposited energy in the WCD identifies electron/positron from muon (and other particles) events. As can be appreciated from figure 4 , there are two clear humps that overlap around momentum of $\approx 0.3 \mathrm{GeV} / \mathrm{c}$ or $\approx 20 \mathrm{MeV}$. The first hump $(\approx 100 \mathrm{MeV})$ denotes the electromagnetic component (electron/positrons) of the extended atmospheric shower, and the second one $(\approx 300 \mathrm{MeV})$ is consistent with muon energy deposited in the WCD. From this plot, it is clear that muon events -backward, soft, and hard muons - are in the energy range of $180 \mathrm{MeV}<E_{\text {loss }}<400 \mathrm{MeV}$ and represent only about 34\% of the WCDhodoscope event occurrences. The other $66 \%$ of data is composed by ( $\mathrm{e}^{ \pm}$) hits under $180 \mathrm{MeV}$ and multiple particle cases above $400 \mathrm{MeV}$ (See [Asorey et al., 2015; Vásquez-Ramírez, 2019]).

- Scattered particles and mini young showers: Low-energy cosmic muons $(0.5 \mathrm{GeV})$ scattered after interacting with the surface of the target impact the detectors (see figure 3), but for higher energies, they are negligible [Gómez et al., 2017]. Thus, we fix a threshold for our estimation on $\approx 10 \mathrm{GeV}$ as it is clear in figure 8 .

- Albedo Noise: Due to its dimensions and calorimetric properties, the WCD filter most of the backward noise (electrons/positrons and multiple particle events), which causes overestimation in the hodoscope counts [Nishiyama et al., 2016]. Additionally, reverse muons events crossing the WCD are rejected by a devised picosecond Time-of-Flight (ToF) system.

The other possible source of noise that could blur the image is the Coulomb dispersion within the scanned object. In this case, the muon trajectory recorded on the detector does not coincide with the original direction of the impacting muon at the geological edifice (see figure 5). The variation of the angle of the change of trajectory of the muon $\Delta \theta=\theta_{\text {fin }}-\theta_{\text {ini }}$ occurs by its interaction with the nuclei of the atoms that make up the scanned object [Presente et al., 2009; Furlan et al., 2013].

A gaussian can represent the distribution of the multiple Coulomb scattering, with zero mean on the measured value and standard deviation $\sigma \theta$ depending on: the radiation length $L_{0}$, the thickness of the crossed material, $L$, and the muon momentum $p$ [Schultz et al., 2004], i.e

$$
\sigma(\theta) \approx \frac{13.6 \mathrm{MeV}}{\beta p c} \sqrt{\frac{L}{L_{0}}}\left(1+0.038 \ln \left(\frac{L}{L_{0}}\right)\right),
$$

with $\beta c$ the particle velocity (assuming as $\beta c=1$ for the muon) and with $c$ is the velocity of light. To estimate the effect 

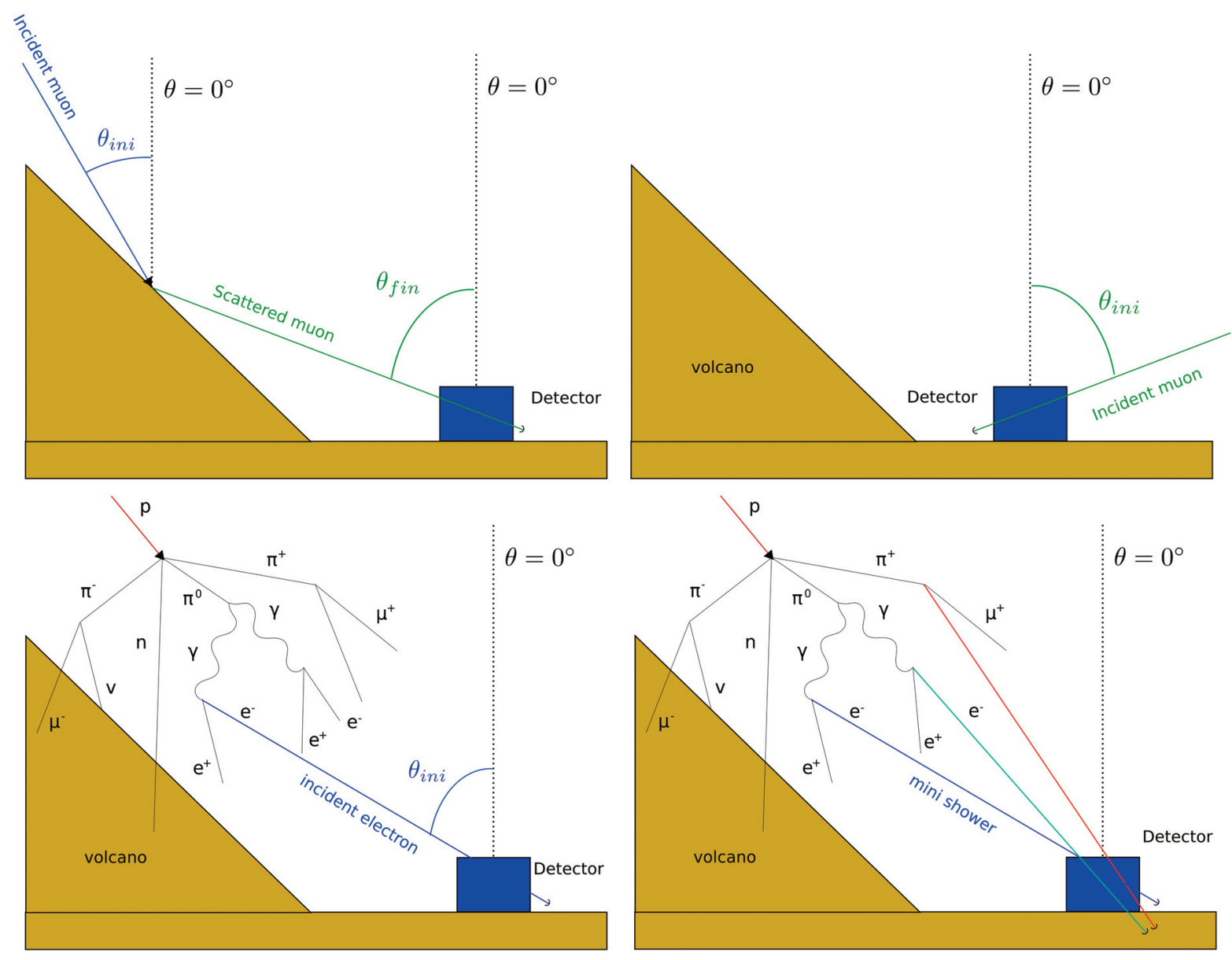

Figure 3. Noise sources in volcano's muography. The background is generated by scattered muons, backward muons, electromagnetic particles of EAS, and mini showers. MuTe is design to reduce these primary noise sources for muography.

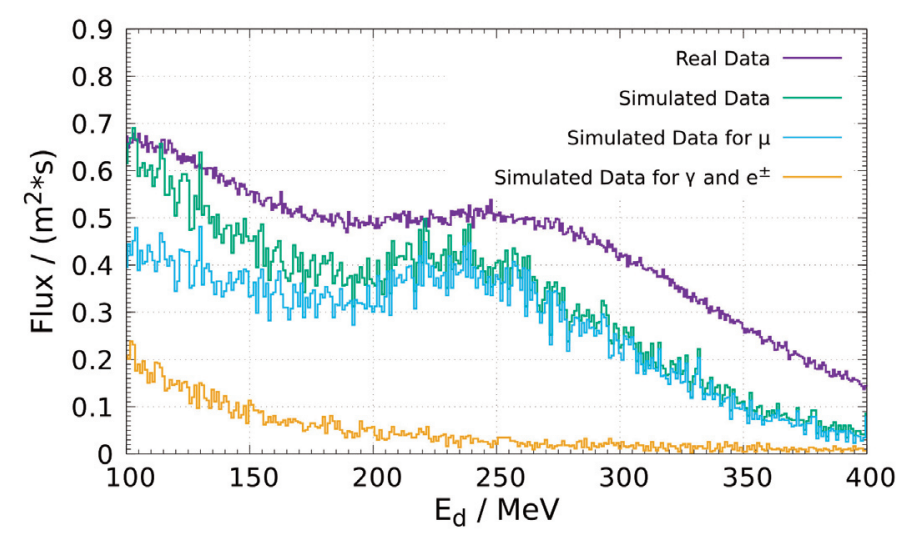

Figure 4. Histogram of particles registered by the WCD as a function of their energy deposited into the detector $\left(E_{d}\right)$ in $\mathrm{MeV}$. The purple line represents real data, while the green one Geant4 simulated data. Because in the simulation it is possible to identify each type of particle: the blueline represents the energy deposited by muon particles, whereas the yellow one corresponds to $\mathrm{E}_{\mathrm{d}}$ by electromagnetic component ( $\mathrm{e} \pm$ and $\gamma$ ). From $200 \mathrm{MeV}$ to $300 \mathrm{MeV}$ muons dominate and the influence of the electromagnetic component increases at lower energies, below 150 $\mathrm{MeV}$. It is remarkable that the $\mathrm{E}_{\mathrm{d}}$ measured by the WCD allows us to distinguish muon from the electromagnetic component of the shower. 


\section{Alejandra Vesga-Ramírez et al.}

of the Coulomb scattering on angular deviation for particle trajectories, we prepared a GEANT4 simulation propagating $10^{4}$ muons impinging the geological edifice with $1000 \mathrm{GeV}$.

The assumed standard rock parameters are $\rho=2.65 \mathrm{~g} / \mathrm{cm}^{3},\left\langle Z / A>=5.5\right.$ and $\left\langle Z^{2} / A>=5.5\right.$, where $\rho$ is rock mass density, $A$, denotes the atomic weight and $Z$ represents the atomic number of the penetrated material [Groom, 2001; Olive et al., 2014].

We have found that the Coulomb noise is negligible. The muons impinging the geological edifice with $1000 \mathrm{GeV}$ -crossing $1000 \mathrm{~m}$ and emerging with few $\mathrm{GeV}$ - only experiment a deviation with $\sigma_{\theta \mathrm{Y}} \approx \sigma_{\theta \mathrm{Z}} \approx 1^{\circ}$. This calculation has been considered in detail in a published paper [Peña-Rodríguez et al., 2020].
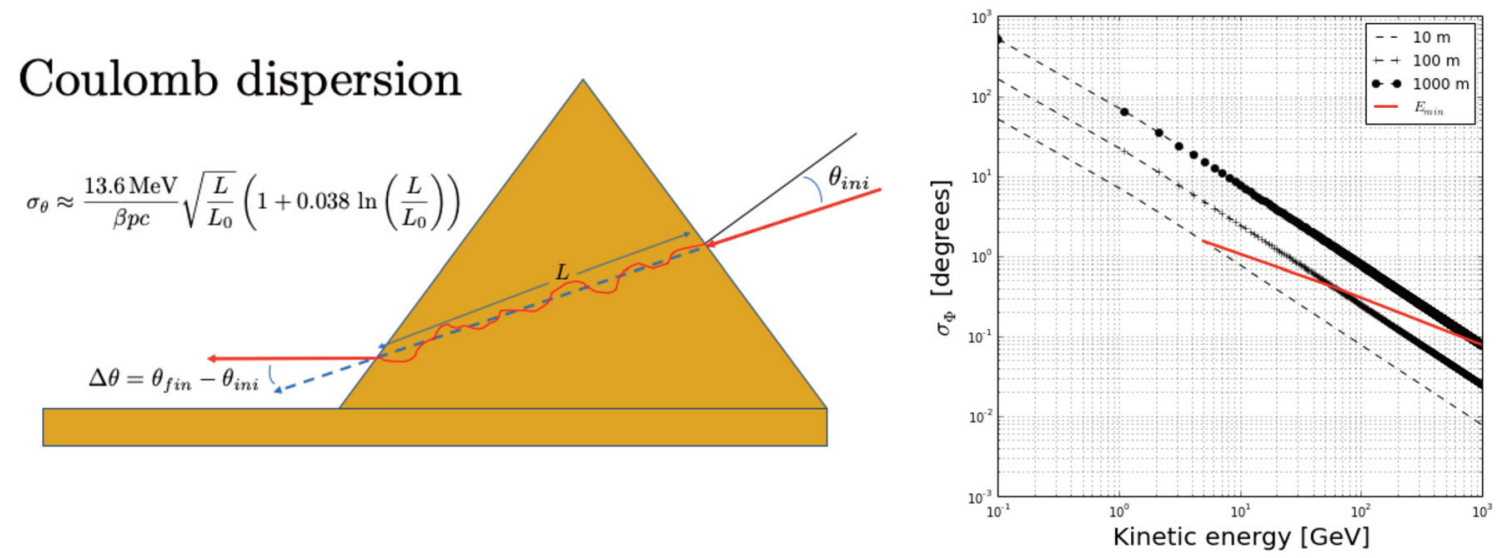

Figure 5. The left plate illustrates the variation of the angle of the crossing muon flux $\Delta \theta=\theta_{\text {fin }}-\theta_{\text {ini }}$ occurring due to the interaction of the crossing muon with nuclei of atoms that conform to the scanned object. The right plate displays the angular dispersion of atmospheric muons crossing $10 \mathrm{~m}, 100 \mathrm{~m}$, and $1000 \mathrm{~m}$ of standard rock. The red line represents the threshold minimum energy to emerge from the geological edifice.

\subsection{Telescope acceptance}

The acceptance of the instrument is a convolution of the telescope geometry (number of pixels, pixel size, and panel separation) and it is obtained multiplying the detection area by the angular resolution, i.e.

$$
T\left(r_{m n}\right)=S\left(r_{m n}\right) \times \delta \Omega\left(r_{m n}\right),
$$

where $r_{m n}$ represents each discrete muon incoming direction, which for an array of two panels with $N_{x} \times N_{y}$ pixels we can identify $\left(2 N_{x}-1\right)\left(2 N_{y}-1\right)$ different particle trajectories [Lesparre et al, 2010]. Moreover, the number of incident particles $N(\varrho)$ can be expressed as

$$
N(\varrho)=\Delta T \times \mathcal{T} \times I(\varrho),
$$

and $I(\varrho)$ is the integrated flux (measured in $\mathrm{cm}^{-2} \mathrm{sr}^{-1} \mathrm{~s}^{-1}$ ), $\mathcal{T}$ represents the acceptance (measured in $\mathrm{cm}^{2} \mathrm{sr}$ ) and $\Delta T$ designates the time exposure (in seconds). It is possible to obtain a simple relationship between the exposure time and the desired opacity resolution as

$$
\Delta T \times \mathcal{T} \times \frac{\Delta I^{2}\left(\varrho_{0}, \delta \varrho\right)}{I\left(\varrho_{0}\right)}>C,
$$


with $\Delta I^{2}\left(\varrho_{0}+\delta \varrho\right)$ the flux variation due to the different opacities $\varrho_{0}$ and $\varrho_{0}+\delta \varrho$, and $C$ is a parameter measuring the confidence level in terms of the standard deviation of the measurement. The above expression gives a bound for the minimum exposure time needed to distinguish opacity differences across the geological object [Lesparre et al., 2010].

In figure 6 we display the angular resolution and the acceptance function for our telescope (with 900 pixels and 3481 discrete $r_{m n}$ directions). For a panel separation of $200 \mathrm{~cm}$, the total angular aperture of our telescope is roughly $582 \mathrm{mrad}$ with the maximum point at $1.6 \times 10^{-3} \mathrm{sr}$ and, as expected, the largest detection surface corresponds to the normal direction $r_{00}$, reaching $\approx 6 \mathrm{~cm}^{2} \mathrm{sr}$.
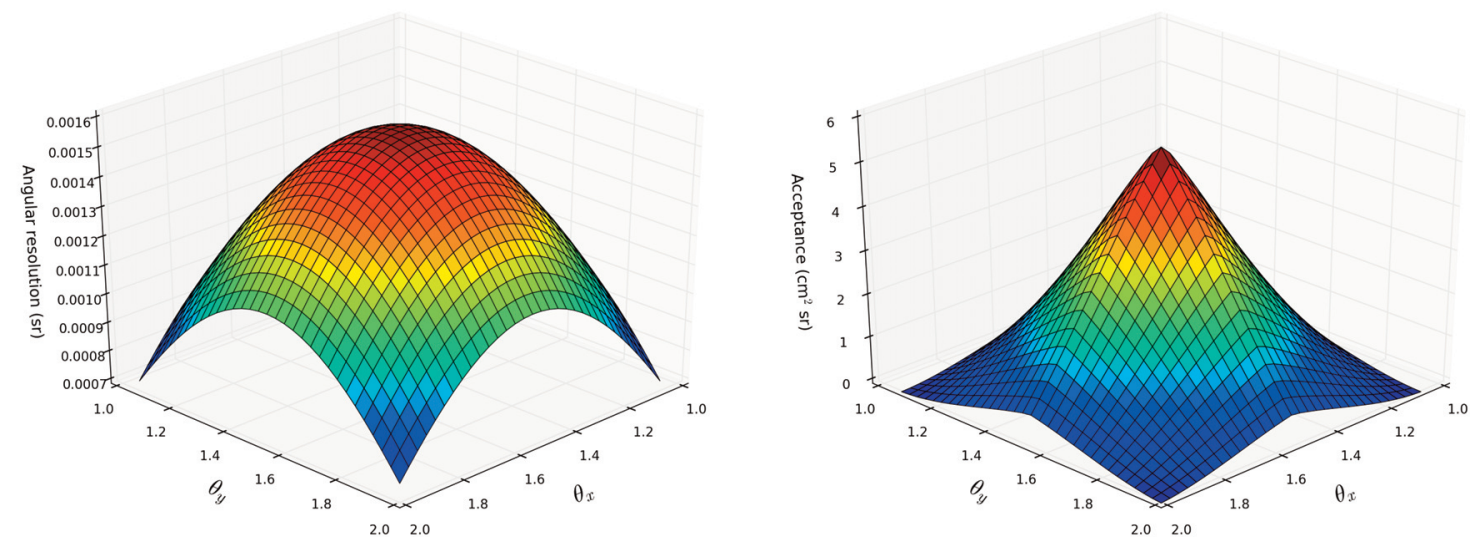

Figure 6. Angular resolution (sr) and acceptance function (cm2sr) of MuTe. Each detection panel has $\mathrm{N}_{\mathrm{x}}=\mathrm{N}_{\mathrm{y}}=30$, 4-cm wide scintillator bars, shaping 900 pixels of $16 \mathrm{~cm}^{2}$ of detecting area. For this number of pixels there are 3481 discrete $r_{m n}$ possible incoming directions.

\section{Machín, Chiles, Cerro Negro and Galeras Volcanoes}

In this section we shall first present a detailed study of the muon propagation across the Machín volcano and calculate the corresponding exposure times for four observation points. We shall also display estimations of the outgoing muon flux from the Machín dome that could be detected by our muon telescope. Secondly, we also display a ray-tracing analysis for muon propagation for three other active Colombia volcanoes: Chiles, Cerro Negro, and Galeras.

It should be emphasized that almost all Colombian inland volcanoes are surrounded by other geological structures that screen the atmospheric muon flux. Thus only a few potential observation points are available.

From the information gathered, we identify some critical parameters that could limit the application of muography in Colombian inland volcanoes and devise a "rule of thumb" criteria to identify possible muography volcano candidates.

\subsection{Detailed study of the flux from the Machín volcano}

We start our study with Machín volcano because it is one of the most dangerous active volcanoes in Colombia. It has an average height of 2750 m.a.s.l; a crater of $2.4 \mathrm{~km}$ of diameter blended into the landscape of its nearby topography, which makes it practically invisible and increases the risk for the surrounding population. Additionally, the morphological similarities between Chichonal and Machín volcanoes -both are considered stratovolcanoes and went unnoticed for decades [Rubio Sánchez, 1985; Macías, 2006]- is impressive. The resemblances of these two volcanic buildings amaze and, the chipping of the eruption of the Chichonal -the largest in the history of México, with an affectation of almost $100 \mathrm{~km}$ around -should alert about the potential danger of Machín. 


\section{Alejandra Vesga-Ramírez et al.}

\subsubsection{Cosmic ray spectral composition at the Machín volcano}

We implement the simulation chain described in section 3.1 to estimate the spectral composition of the open sky particle flux, $\Phi_{\mathrm{os}}$, at the top of Machín volcano $\left(4^{\circ} 29^{\prime} \mathrm{N} 75^{\circ} 22^{\prime} \mathrm{W}\right)$. Figure 7 displays the expected momentum spectra for the open sky flux of secondaries at the geographic coordinates of Cerro Machín. Notice that the angular integrated flux is dominated by muons, which could reach momentums up to $10 \mathrm{TeV} / \mathrm{c}$ but with the low occurrence, while the most probable muons arrive on average with the energy of $4 \mathrm{GeV} / \mathrm{c}$. Notice that this open sky secondary flux corresponds to the simulated \& detected energy deposited in the WCD illustrated in plot 4.

The CoRsiKa simulations executed at the top of Machín volcano, have the following set of parameters: Latitude: 4.48N, Longitude: -75.39W; Magnetic Field (https://www.ngdc.noaa.gov/geomag/calculators/magcalc.shtml\#igrfwmm): North $B_{X}=26.91 \mu \mathrm{T}$ and vertical $B_{Z}=14.37 \mu \mathrm{T}$; Flux time: $24 \mathrm{~h}=86400 \mathrm{~s}$; Arriving altitude: 2450 m.a.s.1.; total number of simulations corresponds to 57.75 days. The zenith incidence of primaries are between $0^{\circ}$ and $90^{\circ}$ (all range) and the primary energies ( $90 \%$ of protons and $10 \%$ other heavier nuclei) are in the range of $5 \mathrm{GeV}$ and $10^{6} \mathrm{GeV}$. We also select the "tropical US Standard" atmospheric model, a volumetric detector for flux calculations, standard energy cuts and rigidity cutoff.
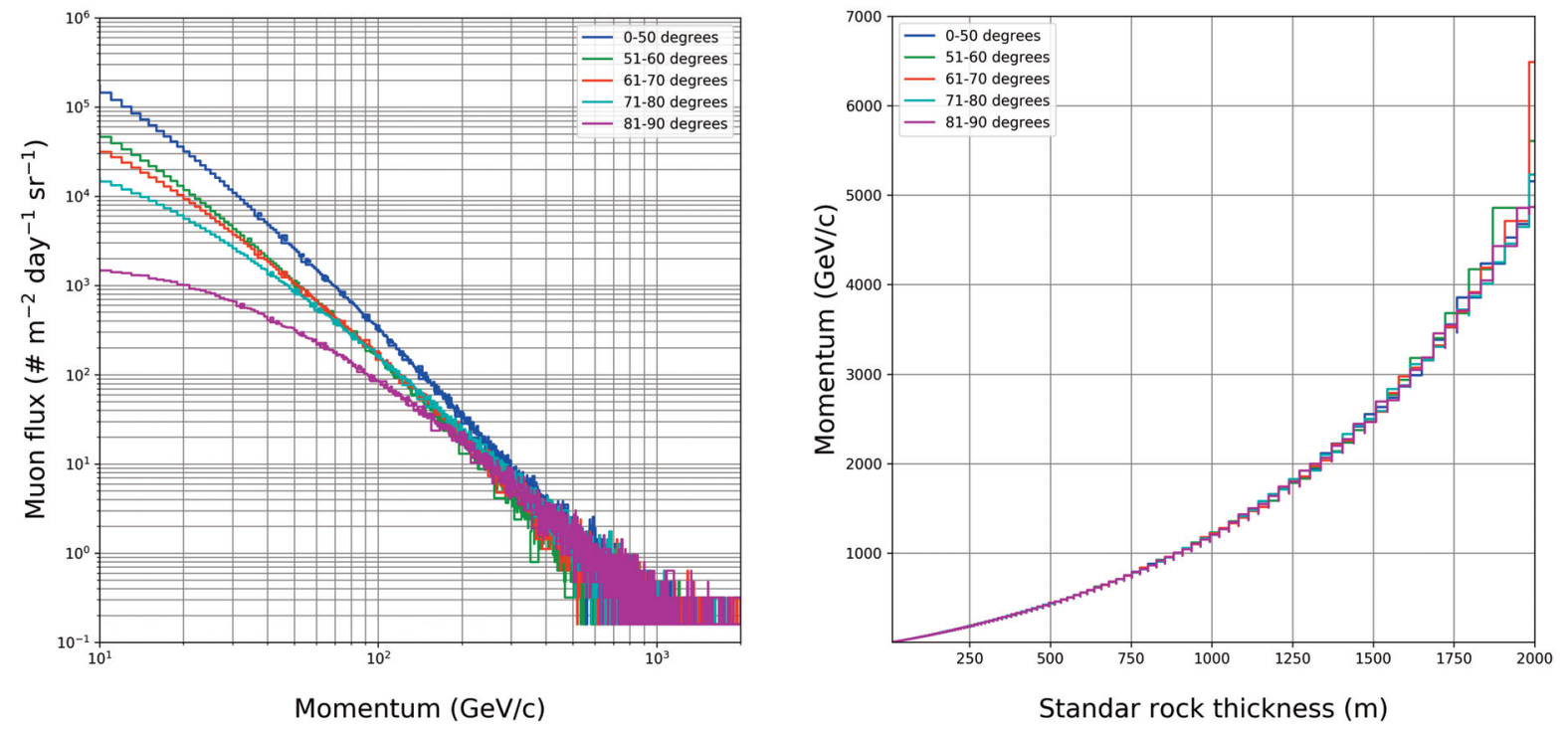

Figure 7. The integrated spectrum of secondaries at the top of Cerro Machín. At the highest momentum of the background, the flux is dominated by muons. It is noticeable that muons could reach momentums up to $10 \mathrm{TeV} / \mathrm{c}$ but with low occurrence, while the most probable muons arrive on average with an energy of $4 \mathrm{GeV} / \mathrm{c}$.

\subsubsection{Muon propagation through the Machín volcano}

Next, we calculate the differential flux of muons at the above mentioned four observational points as a function of the direction of arrival and determine the maximum possible depth that can be observed from each point. This is shown in the left plate of figure 8, where we display the momentum spectra for muons emerging in five angular bins after crossing a standard variable rock with density $2.65 \mathrm{~g} / \mathrm{cm}^{3}$, measured the point $\mathrm{P}_{1 \mathrm{M}}$ of Machín volcano. As it can be clearly appreciated, the muon flux decreases considerately reaching $1 \mathrm{~cm}^{-2} \mathrm{sr}^{-1} \mathrm{day}^{-1}$ for $p_{\mu} \approx 500 \mathrm{GeV} / \mathrm{c}$.

We have employed the topography from the NASA Shuttle Radar Topography Mission global digital elevation model of the Earth (See: http://www2.jpl.nasa.gov/srtm/), with resolution of $90 \mathrm{~m} \times 90 \mathrm{~m}$ (see left plate in figure 9 for the particular case of the Machín volcano). Next, we calculate all the possible distances crossed by each muon path integrating equation (2) and (1) for standard-rock-model dome, with the coefficients $a(E)$ and $b(E)$ obtained from the Particle Data Group [Olive et al., 2014] (Tables on: http://pdg.lbl.gov/2011/AtomicNuclearProperties). 


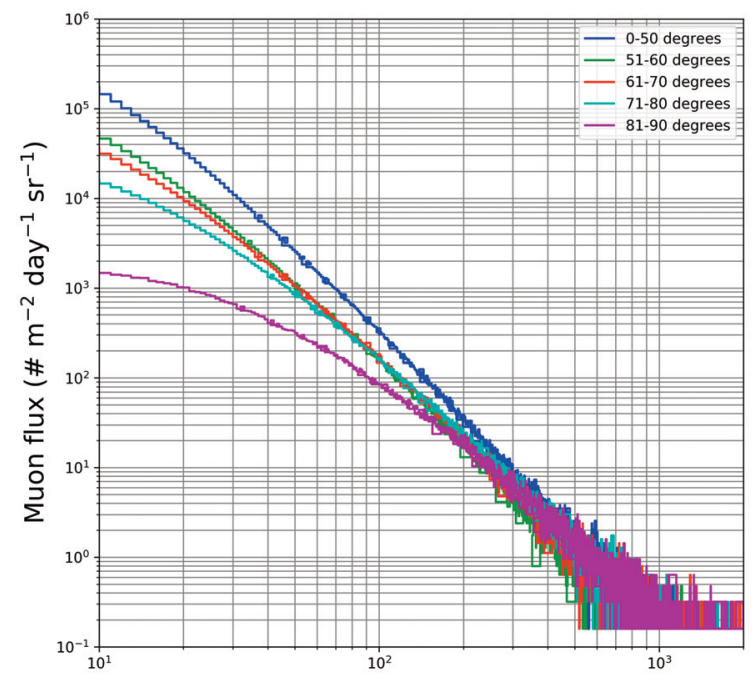

Momentum (GeV/c)

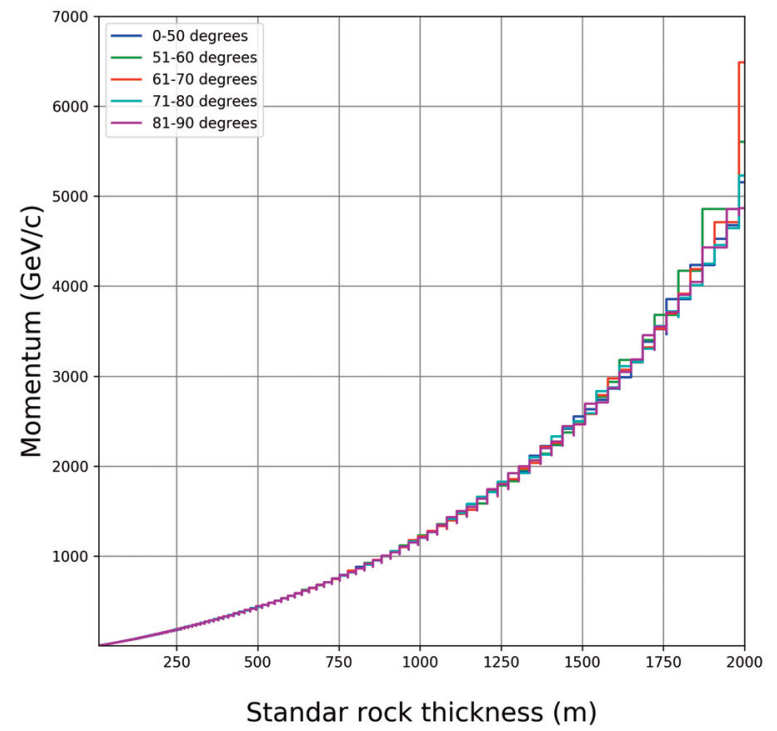

Figure 8. Left plate displays the momentum spectra for muons emerging in five angular bins after crossing a variable standard rock with density $2.65 \mathrm{~g} / \mathrm{cm}^{3}$, measured at the point $\mathrm{P}_{1 \mathrm{M}}$ of Cerro Machín volcano. At $\mathrm{p}_{\mu} \approx 500 \mathrm{GeV} / \mathrm{c}$, the integrated flux is $1 \mathrm{~cm}^{-2} \mathrm{sr}^{-1} \mathrm{day}^{-1}$ and, as expected, muons with zenith angles close to the horizontal decrease by a factor of 100 with respect to those with more vertical angles of incidence. Right plate illustrates the muon energy needed to cross standard rock $\left(2.65 \mathrm{~g} / \mathrm{cm}^{3}\right)$ thickness.
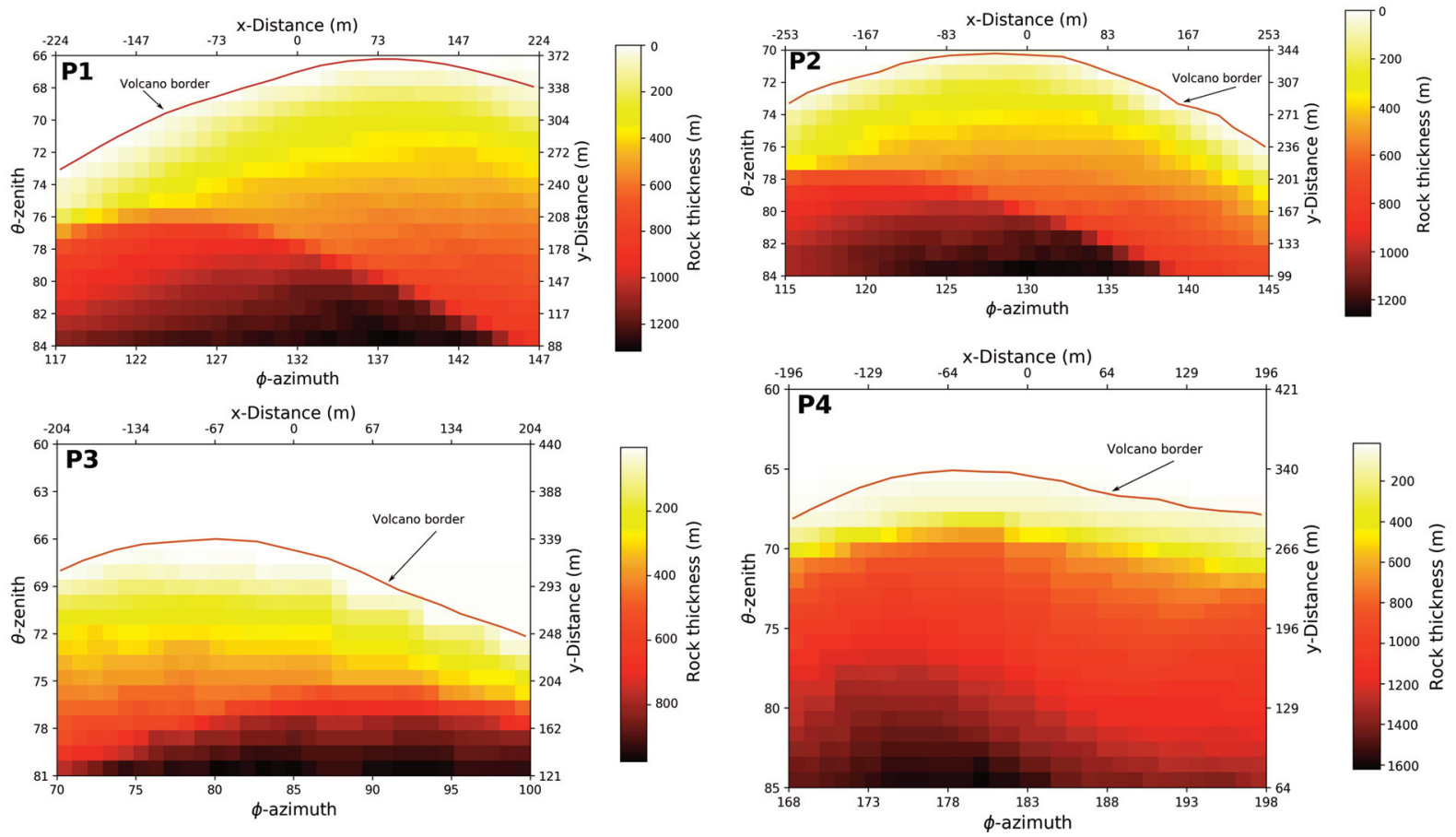

Figure 9. Particle trajectories crossing Cerro Machín volcanic structure to the observation points $\mathrm{P}_{1 \mathrm{M}}, \mathrm{P}_{2 \mathrm{M}}, \mathrm{P}_{3 \mathrm{M}}$ and $\mathrm{P}_{4 \mathrm{M}}$. Notice, for example, that for $\mathrm{P} 1 \mathrm{M}$ observation point, muons with zenith angles $\theta>70^{\circ}$ travel distances exceeding 900 meters. The topography was obtained from NASA Shuttle Radar Topography Mission global digital elevation model of Earth, with SRTM3 resolution $90 \mathrm{~m} \times 90 \mathrm{~m}$. 


\section{Alejandra Vesga-Ramírez et al.}

At Cerro Machín we have identified four observation points: $\mathrm{P}_{1 \mathrm{M}}, \mathrm{P}_{2 \mathrm{M}}, \mathrm{P}_{3 \mathrm{M}}$ and $\mathrm{P}_{4 \mathrm{M}}$ around it (see Table 1). As we have mentioned before, these particular points have been identified because they are not screened by any geological structured behind. Figure 9 displays the ray-tracing technique implemented for those points with the corresponding muon propagation distance through the topography, as well as the angular distribution of these distances around the upper part of the volcano. Emerging muons with these trajectories have crossed about 600 meters of rock within the geological structure.

\begin{tabular}{ccccc} 
Cerro Machín points & $\mathbf{P}_{\mathbf{1 M}}$ & $\mathbf{P}_{\mathbf{2 M}}$ & $\mathbf{P}_{\mathbf{3 M}}$ & $\mathbf{P}_{\mathbf{4 M}}$ \\
\hline Latitude $\left({ }^{\circ} \mathrm{N}\right)$ & 4.492298 & 4.491984 & 4.487338 & 4.494946 \\
\hline Longitude $\left({ }^{\circ} \mathrm{W}\right)$ & -75.381092 & -75.380085 & -75.379510 & -75.388110 \\
\hline Distance to edifice center $(\mathrm{m})$ & 836 & 946 & 762 & 730 \\
\hline Maximum observed depth $(\mathrm{m})$ & 208 & 228 & 250 & 190 \\
\hline
\end{tabular}

Table 1. Feasible observation points at Cerro Machín volcano ( $\left.4^{\circ} 29^{\prime} 23.08^{\prime \prime} \mathrm{N}, 75^{\circ} 23^{\prime} 15.39^{\prime} \mathrm{W}\right)$. The maximum observed depth are those points where the emerging muon flux is less than 10-2 muons per $\mathrm{cm}^{2}$ per day, corresponding to zenith angles $\theta \approx 82^{\circ}$.

Figure 10 displays results of 57.75 days muon flux, emerging from the volcano, and measured at the observation points by our panel of $30 \times 30$ pixels with an inter-panel distance of $200 \mathrm{~cm}$. We have set a minimum threshold count of 100 muons/pixel and can reconstruct $59 \times 59$ images. Comparing figures 9 and 10, we appreciate that there are regions where the incoming muon flux is highly absorbed due to the volcano geometry and the long distances traveled by these muons within the volcano could easily exceed 900 meters.
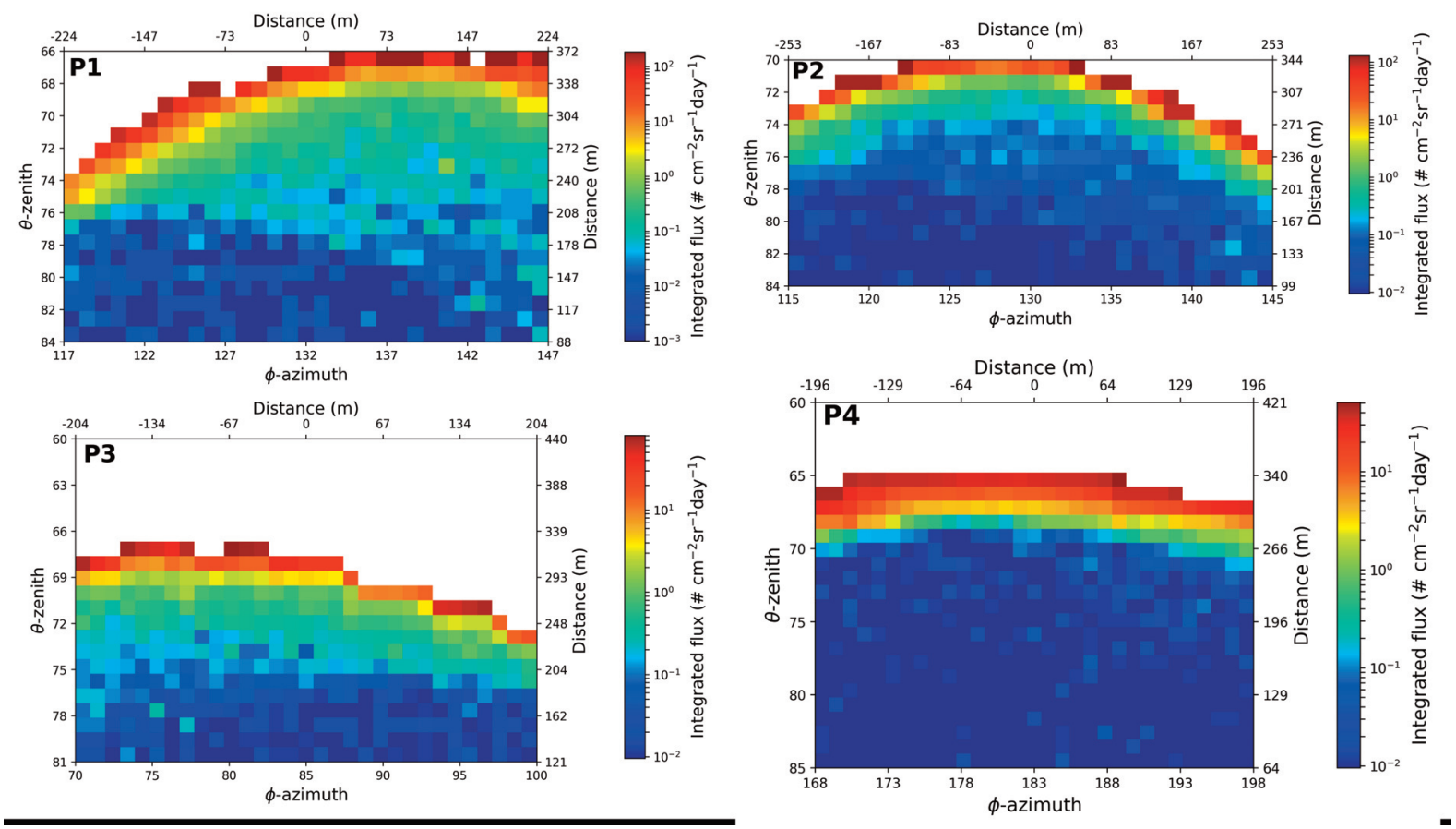

Figure 10. Expected muon flux at $\mathrm{P}_{1 \mathrm{M}}, \mathrm{P}_{2 \mathrm{M}}, \mathrm{P}_{3 \mathrm{M}}$ and $\mathrm{P}_{4 \mathrm{M}}$ observation points in Cerro Machín, as a function of the direction of incidence. Integrating equation (2) we obtain that muons with energies from $0.1 \mathrm{GeV} / \mathrm{c}$ to $10 \mathrm{TeV}$, generate feeble flux: $\approx 10-2$ muon per square centimeter per day at the maximum possible observed depth at zenith angles $\theta \approx 81^{\circ}-84^{\circ}$. White pixels represent open sky muon flux; other colors illustrate the emerging muon flux from the volcano edifice. Comparing this with the previous figure, we can observe that very few muons can cross the structure with traveling distances higher than $1000 \mathrm{~m}$. 
Recently, we performed our simulations but implementing them through MUSIC -for MUon Simulation Code [Kudryavtsev 2009] a precise Monte Carlo muon transport code- and obtained similar results [Moss et al., 2018].

We have found that very few muons - the most penetrate component of the particle shower, ranging from tenths to few thousands of $\mathrm{GeV} / \mathrm{c}^{-}, \approx 10^{-1}$ muons per square meter, per day, (see figure 8 , left plate)- can cross almost $1,000 \mathrm{~m}$ of standard rock (see figure 8, right plate or figures 9 ). Therefore we set 1,500 $\mathrm{m}$ as the upper bound for distances that can be traveled by the most energetic horizontal (Zenith angles $>70$ degrees) muons at any Colombian Volcano. Our analysis also concludes that starting from a few $\mathrm{GeV} / \mathrm{c}$ there is no significant effect of the geo-magnetic correction on the muon flux at any geographical zone in Colombia, but this correction is, in general, essential to determine all the possible particle background flux at other sites with different latitudes [Asorey et al., 2018].

As we have mentioned above, we set a minimum flux of $100 \mu$ pixel and by using equation (5) we estimate the minimum time exposure needed to examine the inner structures of the volcano edifice. In figure 11 we sketch contour lines representing the exposure times required, depending on the point of observation. If we assume an acceptance of $6 \mathrm{~cm}^{-2} \mathrm{sr}$, we will need at least 100 days ( three months) to explore a depth of 150-160 meters.
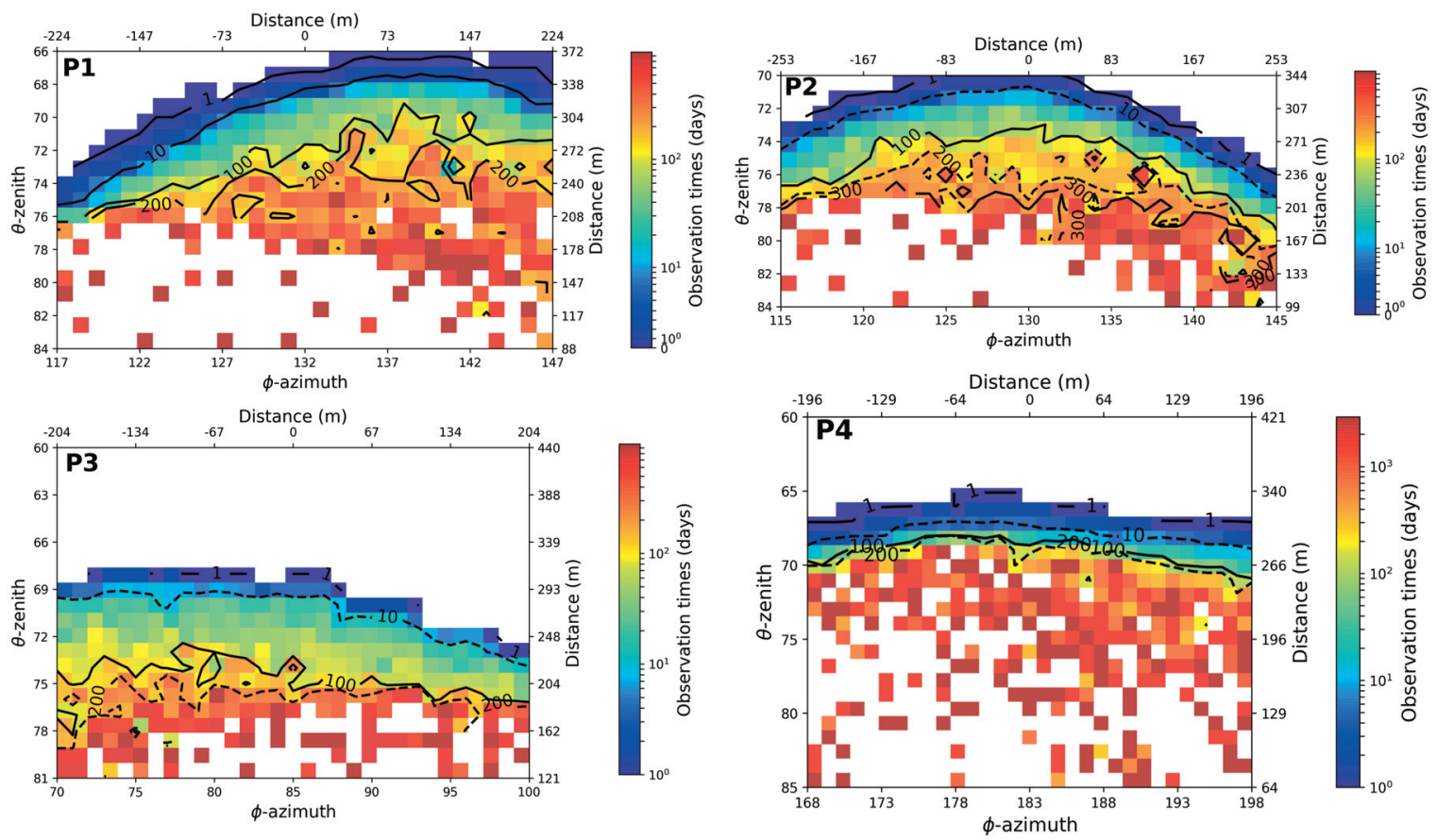

Figure 11. Expected observation times for 100 muons at observation points $\mathrm{P}_{1 \mathrm{M}}, \mathrm{P}_{2 \mathrm{M}}, \mathrm{P}_{3 \mathrm{M}}$ and $\mathrm{P}_{4 \mathrm{M}}$ in Cerro Machín. In this calculation we assume $6 \mathrm{~cm}^{-2} \mathrm{sr}$ acceptance. The results agree that in order to detect 100 muons in all directions an exposure time of 100 days ( $\sim 3$ months) is necessary, achieving a definition at a depth of $150-160$ meters.

As explained before, exposure times, opacity (directional average density) and instrument resolution are related through equation (6) [Lesparre et al., 2010]. There is another variable: the expected exposure times needed to resolve average density differences of $\approx 10 \%$, are shown in figure 12 , for the zenithal range $66^{\circ}<\theta<84^{\circ}$.

\subsection{Ray-tracing for Chiles, Cerro Negro and Galeras}

The idea in this Section is to look for potential observation points where the muon flux travel distance, inside the geological structures, is less than $1,500 \mathrm{~m}$. 


\section{Alejandra Vesga-Ramírez et al.}
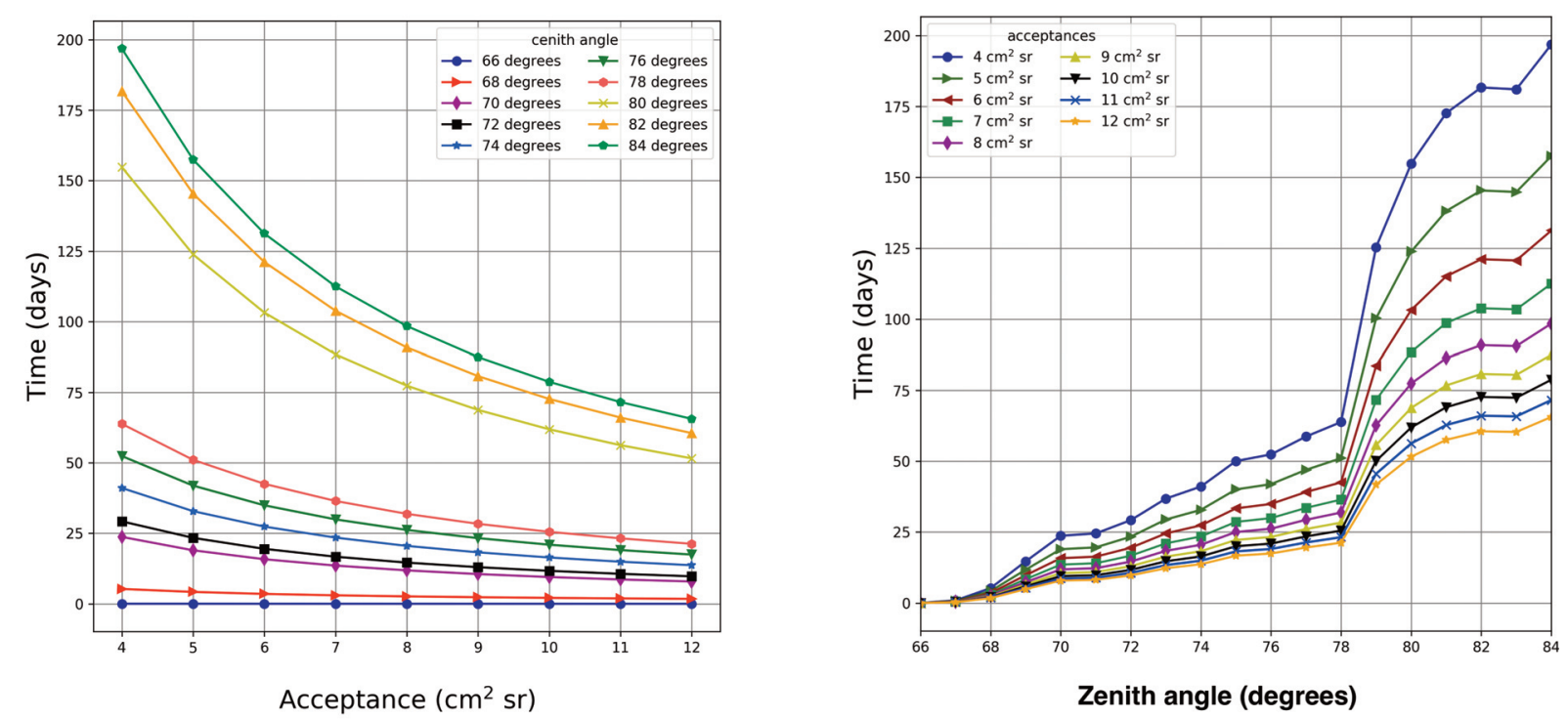

Figure 12. Exposure times for observation point $\mathrm{P}_{1 \mathrm{M}}$ at Cerro Machín needed to identify differences of- $10 \%$ in the averaged directional density for different zenith angles and telescope acceptance. We obtained exposure time lapses between two days and up to more than six months to achieve the desired density resolution, at different zenith angles.

We examine the other three critical Colombian volcanoes using the ray-tracing technique based on the topography, already mentioned, above of the NASA global digital elevation model. First, the code returns the latitude and longitude coordinates in vectors within a matrix of elevation values and redefines the reference system (decimal degrees) to a local reference system (meters). Then we trace the muon trajectory considering in detail the topography around each volcano [Vesga-Ramírez, 2018].

\subsubsection{Observation points at Chiles and Cerro negro volcanoes}

At Chiles we have identified four points (see Table 2) and in figure 13 we can see the ray-tracing technique implemented for $\mathrm{P}_{1 \mathrm{Ch}}, \mathrm{P}_{2 \mathrm{Ch}}, \mathrm{P}_{3 \mathrm{Ch}}$ and $\mathrm{P}_{4 \mathrm{Ch}}$ to determine the distances of muon propagation through the volcano, as well as the angular distribution of these rays around the upper part of the volcano. Although the distances traveled by the muons to the four observation points are less $\tan 1,500 \mathrm{~m}$, the volcano was discarded due to the difficult access to these points.

\begin{tabular}{ccccc} 
Chiles points & $\mathbf{P}_{\mathbf{1 C h}}$ & $\mathbf{P}_{\mathbf{2 C h}}$ & $\mathbf{P}_{\text {3Ch }}$ & $\mathbf{P}_{\mathbf{4}}$ \\
\hline Latitude $\left({ }^{\circ} \mathrm{N}\right)$ & 0.819431 & 0.823917 & 0.829098 & 0.829642 \\
\hline Longitude $\left({ }^{\circ} \mathrm{W}\right)$ & -77.926883 & -77.927034 & -77.930539 & -77.933769 \\
\hline Distance to edifice center $(\mathrm{m})$ & 1050 & 1250 & 1444 & 1450 \\
\hline
\end{tabular}

Table 2. Feasible observation points at Chiles volcano ( $0^{\circ} 49^{\prime} 16.32^{\prime \prime} \mathrm{N},-77^{\circ} 56^{\prime} 6.13^{\prime}$ 'W).

In the case of Cerro Negro we have identified four points around it (see Table 3). 

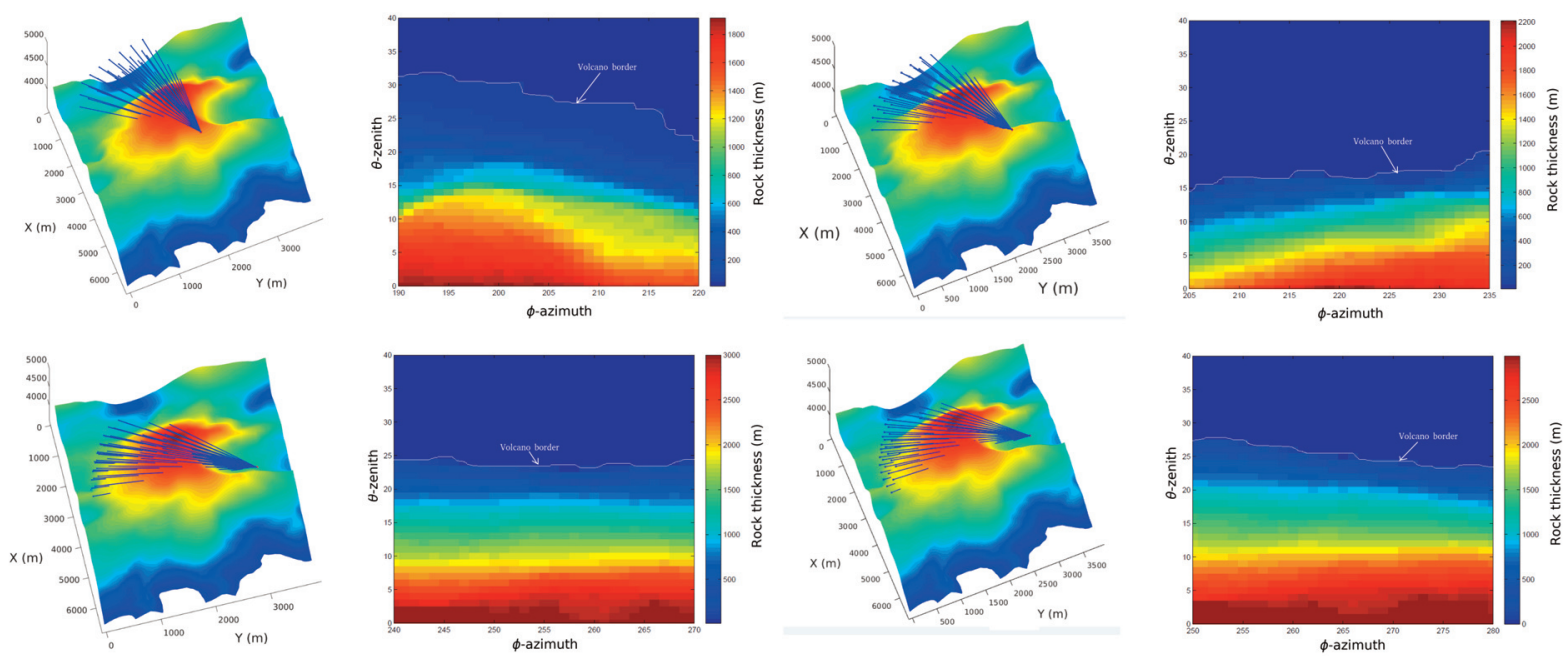

Figure 13. Particle trajectories crossing the Chiles volcano structure to observation point $\mathrm{P}_{1 \mathrm{Ch}}, \mathrm{P}_{2 \mathrm{Ch}}, \mathrm{P}_{3 \mathrm{Ch}}$ and $\mathrm{P}_{4 C h}$. Points $\mathrm{P}_{1 \mathrm{Ch}}$ and $\mathrm{P}_{2 \mathrm{Ch}}$ are in areas that are difficult to access and points $\mathrm{P}_{3 \mathrm{Ch}}$ and $\mathrm{P}_{4 \mathrm{Ch}}$ in high risk areas.

\begin{tabular}{ccccc} 
Cerro Negro points & $\mathbf{P}_{1 \mathrm{CN}}$ & $\mathbf{P}_{2 \mathrm{CN}}$ & $\mathbf{P}_{3 \mathrm{CN}}$ & $\mathbf{P}_{4 \mathrm{CN}}$ \\
\hline Latitude $\left({ }^{\circ} \mathrm{N}\right)$ & 0.826250 & 0.832924 & 0.837090 & 0.840811 \\
\hline Longitude $\left({ }^{\circ} \mathrm{W}\right)$ & -77.954136 & -77.951177 & -77.952412 & -77.954454 \\
\hline Distance to edifice center $(\mathrm{m})$ & 1514 & 1912 & 1961 & 1982 \\
\hline
\end{tabular}

Table 3. Feasible observation points at Cerro Negro volcano $\left(4^{\circ} 29^{\prime} 23.08^{\prime \prime} \mathrm{N},-75^{\circ} 23^{\prime} 15.39^{\prime \prime} \mathrm{W}\right)$.

In figure 14 we can see the ray-tracing technique implemented for $\mathrm{P}_{1 \mathrm{CN}}, \mathrm{P}_{2 \mathrm{CN}}, \mathrm{P}_{3 \mathrm{CN}}$ and $\mathrm{P}_{4 \mathrm{CN}}$ to determine the distances of muon propagation through the Cerro Negro volcano, as well as the angular distribution of these rays around the upper part of the volcano. Notice that to obtain a reasonable muon flux the telescope should be tilted about seven degrees making the depth of investigation very short.

Although the distances traveled by the muons measured from points $\mathrm{P}_{1 \mathrm{CN}}-\mathrm{P}_{4 \mathrm{CN}}$ are less than $1,500 \mathrm{~m}$, this volcano, as well as Chiles, are discarded due to the difficult access to their potential observation points. The Chiles and Cerro Negro volcanoes are on the Colombia-Ecuador border, an intricate zone, where the safety of the scientific personnel and equipment is not guaranteed by either country.

\subsubsection{Observation points at Galeras volcano}

Galeras volcano has been active for more than a million years. Its most recent phase of activity began about 4500 years ago and included six significant eruptions. After quiescence dating from 1948, Galeras renewed its activity in 1988 with the emplacement of a dome, which was destroyed in an explosion in 1992 [Ordón and Cepeda, 1997]. On January 14, 1993, an explosion in Galeras crater killed six visiting scientists and three tourists [Seidl et al., 2003].

The Galera's intense activity and its proximity to San Juan de Pasto city, generate a significant interest to study this Volcano with all techniques available and muography does not escape from this pressure. Several local researchers have made a notable effort in modeling muon transport properties across this dangerous volcano 

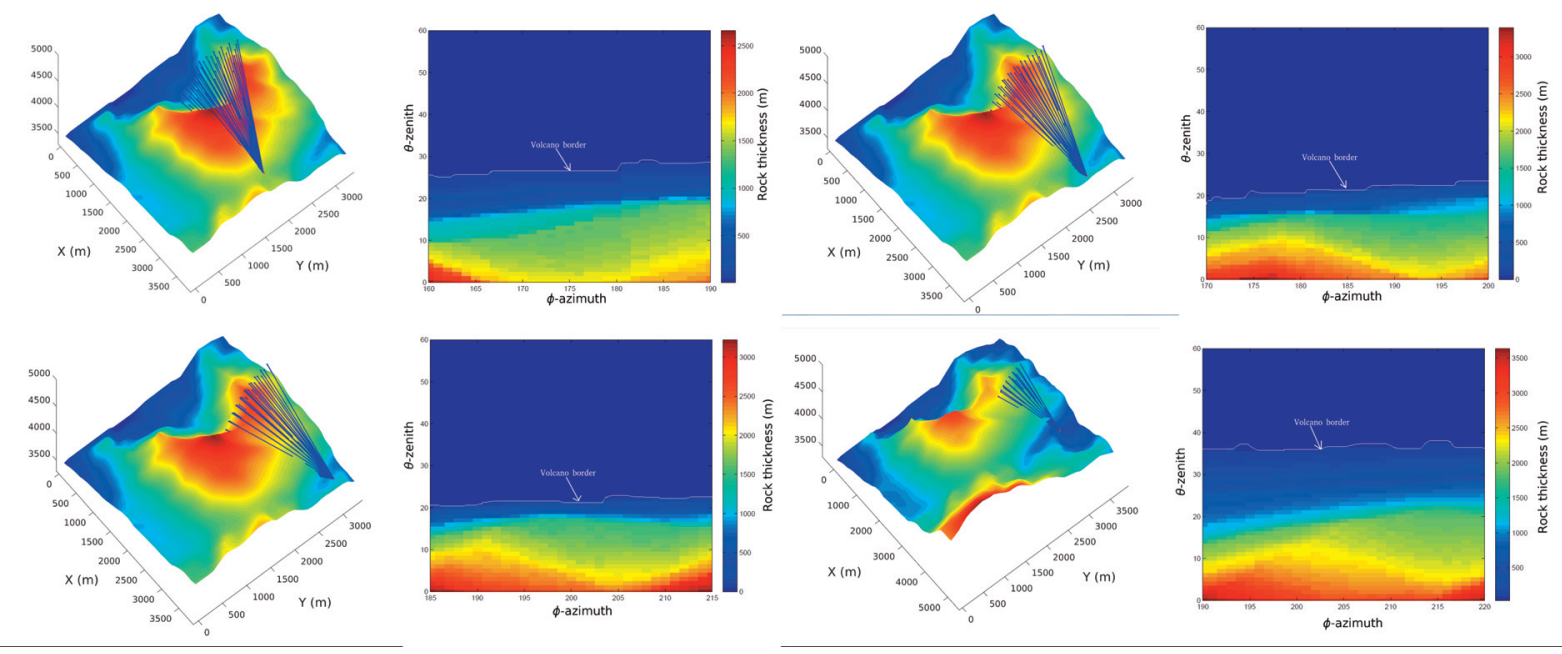

Figure 14. Particle trajectories crossing the Cerro Negro volcanic structure to the observation point $\mathrm{P}_{1 \mathrm{CN}}, \mathrm{P}_{2 \mathrm{CN}}, \mathrm{P}_{3 \mathrm{CN}}$ and $\mathrm{P}_{4 \mathrm{CN}}$.

[Tapia et al., 2016; Guerrero et al., 2019; Torres et al., 2029], and some of them even proposed a design for a muon telescope [Guerrero et al., 2019]. It is not clear which are the geographic coordinates where they intend to place the instrument and what will be the typical exposures times to have a reasonable statistics for the detection. We have proceeded to identify where safe observation points might be to install our MuTe, and how long would it takes to obtain a valuable density distribution. Following this procedure, we have identified four points around Galera Volcano (see Table 4 and figure 15). However, all are in the high volcanic risk area, and so located that the detected muons through the amphitheater and crater overlap, making difficult the analysis (see figure 16).

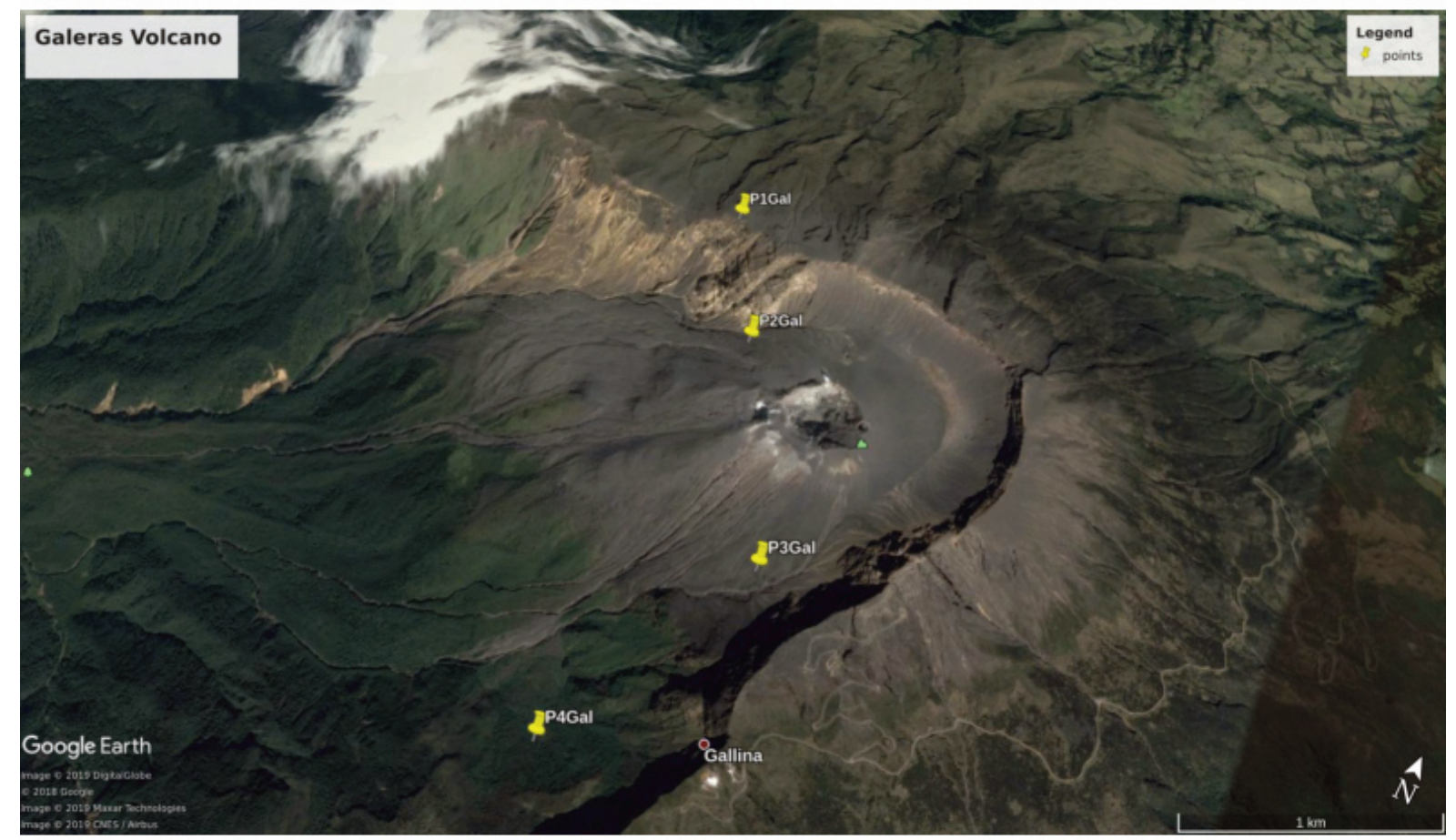

Figure 15. Feasible observation points at Galeras volcano ( $\left.1^{\circ} 13^{\prime} 16.02^{\prime} \mathrm{N}, 77^{\circ} 21^{\prime} 33.09^{\prime} \mathrm{W}\right)$. 

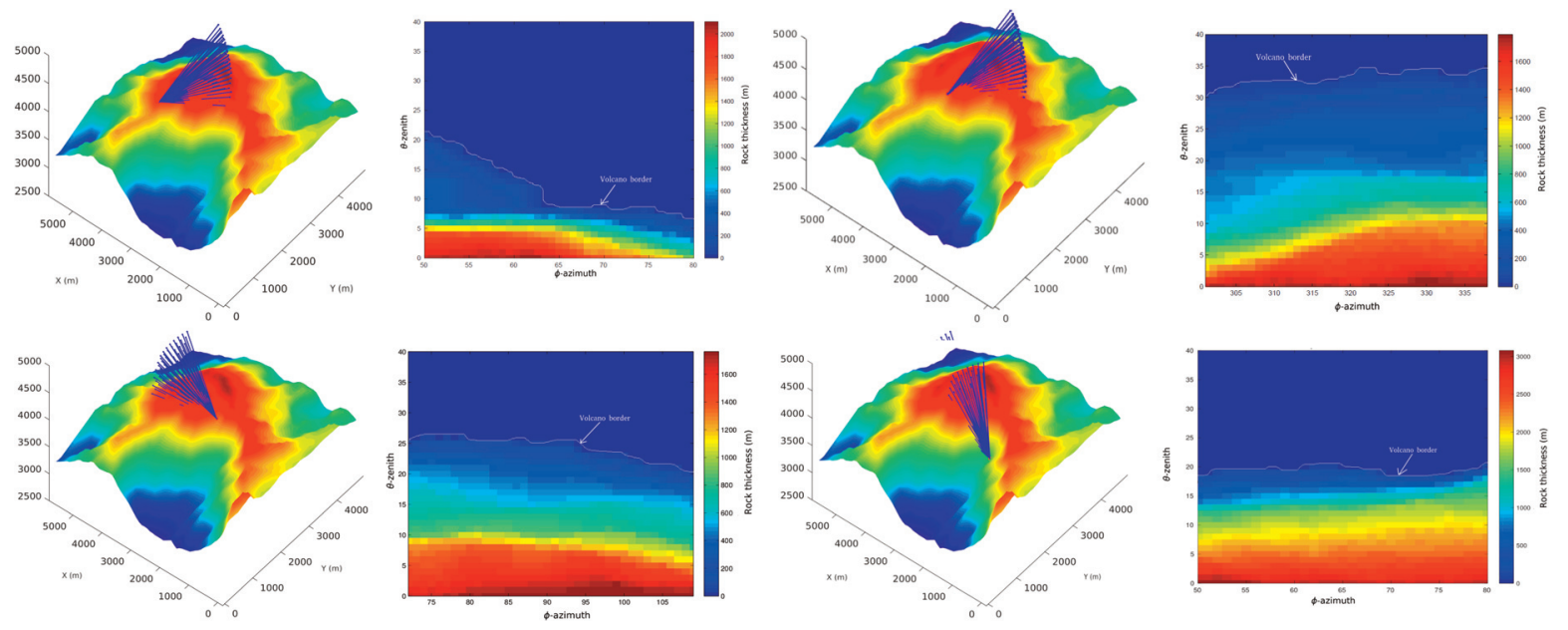

Figure 16. Particle trajectories crossing Galeras volcanic structure to the observation point $P_{1 G}, P_{2 G}, P_{3 G}$ and $P_{4 G}$.

\section{Volcano observation site determination criteria}

Based on the detailed analysis of the Machín volcano, and the ray-tracing studies of the Cerro Negro-Chiles complex and Galeras, we have devised a "rule of thumb" criteria to select the tentative muography observation sites of Colombian volcanoes.

These criteria for determination of the muon observation sites for the Colombian mainland volcanoes,surrounded by other geological structures that could screen the atmospheric muon flux and having insecure access to various regions because of the internal conflict- is qualitatively different from those made on peaceful islands with volcanoes free from the screening of other mountain systems. Thus, to determine muon observation points for active volcanoes in Colombia, we have devised a mix of technical and logistic criteria, which we call the "rule of thumb" criteria that should be fulfilled by the potential sites and which are listed below:

- Criterion 1: At the observational level, is the volcano base width less than 1,500m? This criterion is necessary because there are very few horizontal energetic $\left(3 \times 10^{3} \mathrm{GeV} / \mathrm{c}\right)$ muons and they can only cross $1,500 \mathrm{~m}$ of standard rock (see reference [Nishiyama et al., 2016] and figure 8). Thus, the crossed rock length should be less than this distance from any observation point. This criterion can be appreciated quantitatively for trajectories and flux in the case of Machín volcano (figures 9 and 10), where only a few muons (the most energetic) can cross the geological structure with high zenith angles.

- Criterion 2: Are there tentative observation points where the surrounding topogra-phy does not interfere with the target? Muons impacting the telescope should cross only the structure under study. Nearby mountains and any other geological formations neighboring the target volcano, must not contribute to the opacity. This requisite imposes a severe restriction on the tentative view points for the few observational places where a small window is present, with no mountains or other screening geological structures.

- Criterion 3: Are the sites accessible and secure? Sites must be easily accessible, and the telescope should be securely transported and placed on the field. It is essential to consider: the weight and size of the assembled telescope and its parts; also the quality and accessibility of water resources in the area. Additionally, the volcano to be studied should not be cataloged in a situation of abundant activity due to the danger of volcanic products and processes that may cause severe damage to instrument and personnel. Last but not least the vanishing-internal conflict persisting in several regions of the Colombia countryside and safe access should be taken into account. 


\section{Alejandra Vesga-Ramírez et al.}

We devised these criteria based on the detailed study of Machín volcano and the ray-tracing analysis for 13 Colombian volcanoes. The results of the application of the above criteria are summarized in table 5 and lead to the conclusion that the only Colombian volcano that could be studied through muography is Cerro Machín [Asorey et al., 2017]. We hope that shortly with the end of the internal conflict, Cerro Negro and Chiles will be safely accessible because they are good candidates to be studied with muography, but today they are not yet freely reachable.

\section{Discussion and Conclusions}

In this work, we present the first comprehensive simulation of muon flux for the Machín volcano dome. We have also carried out a ray-tracing analysis for 12 other inland volcanoes in Colombia surrounded by complex topographic environments. After a detailed study from the topography, we have identified the best volcano to be studied, spotted the finest points to place a muon telescope and estimated its time exposures for a significant statistics of muon flux.

The rationale of our new approach stems from a four-step methodology:

1) A "rule of thumb" criteria. We have devised a mix of technical and logistic criteria -the "rule of thumb" criteria- and applied them to 13 Colombian volcanoes. We have found that only Cerro Machín, located at the Cordillera Central $\left(4^{\circ} 29^{\prime} \mathrm{N} 75^{\circ} 22^{\prime} \mathrm{W}\right)$, can be feasibly studied today through muography. Cerro Negro and Chiles could be good candidates shortly.

2) A unabridged simulation of open sky particle spectrum and composition. Corsika has calculated the energy spectrum and composition of open sky secondaries at Cerro Machín and filtered them within Magnetocosmics framework, providing a detailed description of different types of particles in the MeVs to TeVs secondary energy range [Asorey et al., 2015; Suárez-Durán, 2015].

3) A detailed calculation of the emerging muon flux. With the above open sky particle flux and precise topographical information surrounding the volcano, we have simulated the muon propagation inside the geological edifice and estimated the emerging muon flux at four different points around Cerro Machín. This was carried out integrating the energy loss equation 2, with the coefficients $a(E)$ (ionization) and $b(E)$ (radiative losses) from reference [Olive et al., 2014].

4) An estimation of the telescope time exposure. With the emerging muon flux, we have calculated the time exposures of the instrument for an arbitrary statistics of 100 events at each pixel and, different values of the telescope acceptance (see figure 12).

As we have mentioned before, most of the previous muography studied volcanoes -Mount Asama [Tanaka et al., 2007] in Japan; Puy de Dôme [Noli et al., 2017] in France; Mount Etna [Carbone et al., 2014] in Italy; La Soufuriere [Lesparre et al., 2012a, 2012b] in Guadalupe, to mention the most relevant studies- are topographically isolated with a relatively good and accessible observation points. None are surrounded by geological structures screening the scarce high energy horizontal muons. However, the landscape in Colombia -and surely in all other Andean volcanoes- is very different; most of the active volcanoes are along the Cordillera Central, surrounded by higher altitudes shielding cosmic ray flux. Therefore, we developed a methodology to identify the most feasible candidates, and only Cerro Machín emerged as a possibility.

Instead of using phenomenological and pseudo-empirical formulas to estimate the background flux at the volcano site (see [Tanaka et al., 2007] and references therein), we proceeded to simulate its spectrum and composition, at each particular geographical location, with two standard astroparticle tools: Corsika and Magnetocosmics. We found that incident muons range from $0.1 \mathrm{GeV} / \mathrm{c}$ to $10 \mathrm{TeV}$, and the flux of high energy muons is very feeble: $\approx 10$ muons per square meter per day at zenith angles $\theta \approx 82^{\circ}-84^{\circ}$.

With the above simulation as an input, and including precise topographical information, we calculate the propagation of muons through the geological edifice and determine the emerging muon flux that could be detected at several particular observation points around the volcano (see figure 9). We have simulated more than 50 days of muon flux to estimate the minimum time needed to obtain a flux of 100 muons per pixel and found out that we require at least three months of data acquisition to explore the Machín dome (depending on the observation point) at a depth of $\approx 110 \mathrm{~m}$.

Then, to discriminate density variations of $10 \%$, we evaluated time exposures for our hybrid instrument as function of the acceptance. With these preliminary simulation results and by considering the standard configuration 
of our telescope, we have estimated time intervals between 100 to 125 days for the upper end (114-150 m) of the volcano edifice. These results were recently reconfirmed using more precise muon underground propagation codes [Kudryavtsev, 2009; Moss et al., 2018].

We have estimated the effect of the Coulomb scattering on angular deviation for particle trajectories, propagating $10^{4}$ muons impinging the geological edifice with $1000 \mathrm{GeV}$, and found this type of noise, can be considered negligible.

Muography can not image deep volcano structures, but it seems to be useful in determining shallow phenomena with an excellent spatial resolution. This technique can not give direct information on when a volcano will erupt, but it could provide significant insights about possible eruption processes, in the upper end of the edifice. This emerging technique requires significant progress in data analysis, treatment and interpretation of the experimental data obtained. For a bright future, it depends on the synergy between two active international communities: particle physicists and geophysicists [Tanaka, 2016].

Acknowledgments. The authors acknowledge the financial support of Departamento Administrativo de Ciencia, Tecnologíae Innovación of Colombia (ColCiencias) under contract FP44842-082-2015 and to the Programa de Cooperación Nivel II (PCB-II) MINCYT-CONICET-COLCIENCIAS 2015, under project CO/15/02. We are also very thankful to LAGO and to the Pierre Auger Collaboration for their continuous support. The simulations in this work were partially possible thanks to The Red Iberoamericana de Computación de Altas Prestaciones (RICAP, 517RT0529), co-funded by the Programa Iberoamericano de Ciencia y Tecnología para el Desarrollo (CYTED) under its Thematic Networks Call. We also thank the computational support from the Universidad Industrial de Santander (SC3UIS) High Performance and Scientific Computing Centre. Finally, we would like to thank Vicerrectoría Investigación y Extensión Universidad Industrial de Santander for its permanent sponsorship. One of us, DSP, wants to thank the Escuela de Física, the Grupo de Investigación en Relatividad y Gravitación, Grupo Halley de Astronomía y Ciencias Aeroespaciales and Vicerrectoría Investigación y Extensión of Universidad Industrial de Santander for the hospitality during his postdoctoral fellowship. Our simulation codes can be found at https://github.com/AstroparticulasBucaramanga and other pertinent data can be also obtained from https://zenodo.org/record/807741\#.WUMdlMaZPex.

\section{References}

Agostinelli, S., J. Allison, K. Amako, J. Apostolakis, H. Araujo, P. Arce, M. Asai, D. Axen,S. Banerjee, G. Barrand, F. Behner, L. Bellagamba, J. Boudreau, L. Broglia, A. Brunengo,H. Burkhardt, S. Chauvie, J. Chuma, R. Chytracek, G. Cooperman, G. Cosmo, P. Degtyarenko,A. Dell’Acqua, G. Depaola, D. Dietrich, R. Enami, A. Feliciello, C. Ferguson, H. Fesefeldt,G. Folger, F. Foppiano, A. Forti, S. Garelli, S. Giani, R. Giannitrapani, D. Gibin, J.J. GómezCadenas, I. González, G. Gracía Abril, G. Greeniaus, W. Greiner, V. Grichine, A. Grossheim,S. Guatelli, P. Gumplinger, R. Hamatsu, K. Hashimoto, H. Hasui, A. Heikkinen, A. Howard,V. Ivanchenko, A. Johnson, F.W. Jones, J. Kallenbach, N. Kanaya, M. Kawabata, Y. Kawabata,M. Kawaguti, S. Kelner, P. Kent, A. Kimura, T. Kodama, R. Kokoulin, M. Kossov, H. Kurashige,E. Lamanna, T. Lampén, V. Lara, V. Lefebure, F. Lei, M. Liendl, W. Lockman, F. Longo,S. Magni, M. Maire, E. Medernach, K. Minamimoto, P. Mora de Freitas, Y. Morita, K. Murakami,M. Nagamatu, R. Nartallo, P. Nieminen, T. Nishimura, K. Ohtsubo, M. Okamura, S. O’Neale,Y. Oohata, K. Paech, J. Perl, A. Pfeiffer, M.G. Pia, F. Ranjard, A. Rybin, S. Sadilov, E. Di Salvo,G. Santin, T. Sasaki, N. Savvas, Y. Sawada, S. Scherer, S. Sei, V. Sirotenko, D. Smith, N. Starkov,H. Stoecker, J. Sulkimo, M. Takahata, S. Tanaka, E. Tcherniaev, E. Safai Tehrani, M. Tropeano,P. Truscott, H. Uno, L. Urban, P. Urban, M. Verderi, A. Walkden, W. Wander, H. Weber, J. P. Wellisch, T. Wenaus, D.C. Williams, D. Wright, T. Yamada, H. Yoshida, and D. Zschiesche (2003). Geant4: a simulation toolkit. Nuclear instruments and methods in physics research section A: Accelerators, Spectrometers, Detectors and Associated Equipment, 506(3):250-303.

Agudelo, A. (2016). Informe técnico de actividad de los volcanes nevado del huila, Puracé y Sotará, durante el periodo de diciembre de 2016. Technical report 12, Reporte Interno, Popayan, Colombia, Servicio Geológico Colombiano.

Aguilar Casalla, C. and D.A Piedrahita Torres (2017). Estratigrafía del cráter y morfología del volcán cerro machín, Colombia. Pregraduate research project, Geology Program, Universidad de Caldas, Manizales, Colombia.

Alvarez, L.W., J.A. Anderson, F. El Bedwei, M. Sharkawi, and L. Yazolino (1970). Search for Hidden Chambers in the 


\section{Alejandra Vesga-Ramírez et al.}

Pyramids. Science, 167(3919):832-839.

Anastasio, A., F. Ambrosino, D. Basta, L. Bonechi, M. Brianzi, A. Bross, S. Callier, A. Caputo, R. Ciaranfi, L. Cimmino, R. D’Alessandro, L. D’Auria, C. de La Taille, S. Energico, F. Garufi, F. Giudicepietro, A. Lauria, G. Macedonio, M. Martini, V. Masone, C. Mattone, M.C. Montesi,P. Noli, M. Orazi, G. Passeggio, R. Peluso, A. Pla-Dalmau, L. Raux, P. Rubinov, G. Saracino,E. Scarlini, G. Scarpato, G. Sekhniaidze, O. Starodubtsev, P. Strolin, A. Taketa, H.K.M. Tanaka, and A. Vanzanella (2013). The mu-ray detector for muon radiography of volcanoes. Nuclear Instruments and Methods in Physics Research Section A: Accelerators, Spectrometers, Detectors and Associated Equipment, 732:423 - 426, 2013. Vienna Conference on Instrumentation.

Asorey, H., A. Balaguera-Rojas, L. A. Núñez, J. D. Sanabria-Gómez, C. Sarmiento-Cano, M. Suárez-Durán, M. ValenciaOtero, and A. Vesga-Ramírez (2017). Astroparticle Techniques: Colombia Active Volcano Candidates for Muon Telescope Observation Sites. In Revista Mexicana de Astronomía y Astrofisica Conference Series, volume 49 of Revista Mexicana de Astronomia y Astrofisica Conference Series, pages 54-54.

Asorey, H., R. Calderón-Ardila, C. R. Carvajal-Bohorquez, S. Hernández-Barajas, L. Martínez-Ramírez, A. JaimesMotta, F. León-Carreño, J. Peña-Rodríguez, J. Pisco-Guavabe, J.D. Sanabria-Gómez, M. Suárez-Durán, A. Vásquez-Ramírez, K. Forero-Gutiérrez, J. Salamanca-Coy, L. A. Núñez, and D. Sierra-Porta (2018). Astroparticle projects at the eastern Colombia region: facilities and instrumentation Scientia et technica, 23(3):391-396.

Asorey, H., R. Calderón-Ardila, K. Forero-Gutiérrez, L.A. Núñez, J. Peña-Rodríguez, J. Salamanca-Coy, D. SanabriaGómez, J. Sánchez-Villafrades, and D. Sierra-Porta (2018). minimute: A muon telescope prototype for studying volcanic structures with cosmic ray flux. Scientia et technica, 23(3):386-390

Asorey, H., S. Dasso, L.A. Núñez, Y. Pérez, C. Sarmiento-Cano, M. Suárez-Durán, and the LAGO Collaboration (2015). The LAGO space weather program: Directional geomagnetic effects, background fluence calculations and multi-spectral data analysis. In The 34th International Cosmic Ray Conference, volume PoS (ICRC2015), 142.

Asorey, H., L. A. Núñez, and M. Suárez-Durán (2018). Preliminary results from the Latin American Giant Observatory space weather simulation chain. Space Weather, 16(5):461-475.

Borrero, C., L.M. Toro, M. Alvarán, and H. Castillo (2009). Geochemistry and tectonic controls of the effusive activity related with the ancestral Nevado del Ruiz volcano, Colombia. Geofísica internacional, 48(1):149-169.

Calderón-Ardila, R., H. Asorey, L. A. Núñez, and LAGO Collaboration (2015). Geant4 based simulation of the water cherenkov detectors of the LAGO project. Nuclear and Particle Physics Proceedings, pages 424-426.

Calvache, M. L., G. P. Cortés, and S. N. Williams (1997). Stratigraphy and chronology of the Galeras volcanic complex, Colombia. J. Volcanol. Geothermal Res., 77(1):5-19.

Carbone, D., D. Gibert, J. Marteau, M. Diament, L. Zuccarello, and E. Galichet (2014). An experiment of muon radiography at mt etna (italy). Geophys. J. Int., 196(2):633-643.

Cârloganu, C., V. Niess, S. Béné, E. Busato, P. Dupieux, F. Fehr, P. Gay, D. Miallier, B. Vulpescu, P. Boivin, C. Combaret, P. Labazuy, I. Laktineh, J.-F. Lénat, L. Mirabito, and A. Portal (2013). To-wards a muon radiography of the Puy de Dôme. Geoscientific Instrumentation, Methods and Data Systems, 2(1):55-60.

Cepeda, H., L.A. Murcia, M.L. Monsalve, R.A. Méndez, and A. Núñez (1995). Volcán cerro machín, departamento del tolima, Colombia: Pasado, presente y futuro. Technical report, INGEOMINAS, Informe interno.

Cortés, G.P. and J. Raigosa (1997). A synthesis of the recent activity of Galeras volcano, Colombia: Seven years of continuous surveillance, 1989-1995. J. Volcanol. Geotherm. Res.,77(1):101-114.

Cortés, G.P. (2001). Lahares asociados a la actividad eruptiva del volcán cerro machín. In Memorias VIII Congreso Colombiano de Geología. Manizales, 12p.

Cortés, G.P. (2016). Informe de actividad volcánica segmento norte de Colombia diciembre de 2016. Technical report, Reporte interno, Manizales, Colombia. INGEOMINAS.

Cruz, F. G. and B. A. Chouet (1997). Long-period events, the most characteristic seismicity accompanying the emplacement and extrusion of a lava dome in Galeras volcano, Colombia, in 1991. J. Volcanol. Geothermal Res., 77(1):121-158.

Desorgher, L. (2003). MAGNETOSCOSMICS, Geant4 application for simulating the propagation of cos-mic rays through the Earth magnetosphere. Technical report, Physikalisches Institut, University of Bern, Bern, Germany.

Fesefeldt, H.C. (1985). Technical report pitha-85-02. Technical Report 5001, III Physikalisches Institut, RWTH Aachen Physikzentrum.

Finlay, C. C., S. Maus, C. D. Beggan, T. N. Bondar, A. Chambodut, T. A. Chernova, A. Chulliat,V. P. Golovkov, B. Hamilton, M. Hamoudi, R. Holme, G. Hulot, W. Kuang, B. Langlais, V. Lesur,F. J. Lowes, H. Lühr, S. MacMillan, 
M. Mandea, S. McLean, C. Manoj, M. Menvielle, I. Michaelis,N. Olsen, J. Rauberg, M. Rother, T. J. Sabaka, A. Tangborn, L. Töffner-Clausen, E. Thébault,A. W. P. Thomson, I. Wardinski, Z. Wei, and T. I. Zvereva (2010). International Geomagnetic Reference Field: the eleventh generation. Geophys. J. Int., 183:1216-1230.

Furlan, M., A. Rigoni, S. Vanini, G. Zumerle, P. Checchia, L. Cossutta, G. Bettella, P. Zanuttigh, P. Calvini, L. Dassa, A. Donzella, G. Bonomi, and A. Zenoni (2013). Application of muon tomography to detect radioactive sources hidden in scrap metal containers. In 2013 3rd International Conference on Advancements in Nuclear Instrumentation, Measurement Methods and their Applications (ANIMMA). IEEE.

George, E.P. (1955). Cosmic rays measure overburden of tunnel. Common wealth Engineer, 1:455-457.

Gibert, D., F. Beauducel, Y. Déclais, N. Lesparre, J. Marteau, F. Nicollin, and A. Tarantola (2010). Muon tomography: Plans for observations in the Lesser Antilles. Earth, Planets and Space, 62(2):153-165.

Gómez, H., D. Gibert, C. Goy, K. Jourde, Y. Karyotakis, S. Katsanevas, J. Marteau, M. Rosas-Carbajal, and A. Tonazzo (2017). Forward scattering effects on muon imaging. Journal of Instrumentation, 12(12):P12018

Groom, D. (2001). Muon Stopping Power and Range Tables $10 \mathrm{MeV}-100 \mathrm{TeV}$. Atomic Data and Nuclear Data Tables, 78(2):183-356.

Guerrero, I.D., D.F. Cabrera, J.C. Paz, J.D. Estrada, C.A. Villota, E.A. Velasco, F.E. Fajardo, O. Rodríguez, J. Rodríguez, D. Arturo, D. Dueñas, D. Torres, J. Ramírez, J. Revelo, G. Ortega, D. Benavides, J. Betancourt, A. Tapia, and D.A. Martínez-Caicedo (2019). Design and construction of a muon detector prototype for study the Galeras volcano internal structure. In Journal of Physics: Conference Series, volume 1247, page 012020. IOP Publishing.

Heck, D., J. Knapp, J.N. Capdevielle, G. Schatz, and T. Thouw (1998). Corsika: A Monte Carlo code to simulate extensive air showers. Technical Report FZKA 6019, Forschungszentrum KarlsruheGmbH.

Huggel, C., J.L. Ceballos, B. Pulgarín, J. Ramírez, and J.-C. Thouret (2007). Review and reassessment of hazards owing to volcano-glacier interactions in Colombia. Annals of Glaciology, 45(1):128-136.

Jaimes-Motta, A. (2018). Estimación de la respuesta de un detector Cherenkov de agua al fondo de rayos cósmicos en Bucaramanga (956 m s.n.m). Pregraduate research project, School of Physics, Universidad Industrial de Santander, Bucaramanga, Colombia.

Jourde, K., D. Gibert, J. Marteau, J. Bremond d’Ars, S. Gardien, C. Girerd, J.-C. Ianigro, and D. Carbone (2013). Experimental detection of upward going cosmic particles and consequences for correction of density radiography of volcanoes. Geophys. Res. Lett., 40(24):6334-6339.

Kaiser, R. (2019). Muography: overview and future directions. Philosophical Transactions of the Royal Society A: Mathematical, Phys. Engineering Sci., 377(2137):20180049

Kudryavtsev, V.A. (2009). Muon simulation codes music and musun for underground physics. Comput. Phys. Commun., 180(3):339-346.

Lesparre, N., D. Gibert, J. Marteau, Y. Déclais, D. Carbone, and E. Galichet (2010). Geophysical muon imaging: feasibility and limits. Geophys. J. Int., 183(3):1348-1361.

Lesparre, N., D. Gibert, J. Marteau, J.C. Komorowski, F. Nicollin, and O. Coutant (2012). Density muon radiography of La Soufrière of Guadeloupe volcano: comparison with geological, electrical resistivity and gravity data. Geophys. J. Int., 190(2):1008-1019.

Lesparre, N., J. Marteau, Y. Déclais, D. Gibert, B. Carlus, F. Nicollin, and B. Kergosien (2012). Design and operation of a field telescope for cosmic ray geophysical tomography. Geosci. Istrum. Methods Data Syst., 1(1):33-42.

Macías, J.L. (2006). Geología e historia eruptiva de algunos de los grandes volcanes activos de México. Boletín de la Sociedad Geológica Mexicana, 57(3):379-424.

Marteau, J., D. Gibert, N. Lesparre, F. Nicollin, P. Noli, and F. Giacoppo (2012). Muons tomography applied to geosciences and volcanology. Nuclear Instruments and Methods in Physics Research Section A: Accelerators, Spectrometers, Detectors and Associated Equipment, 695:23-28.

Masías-Meza, J. J. and S. Dasso (2014). Geomagnetic effects on cosmic ray propagation under different conditions for Buenos Aires and Marambio, Argentina. Sun and Geosphere, 9:41-47.

Morishima, K., M. Kuno, A. Nishio, N. Kitagawa, Y. Manabe, M. Moto, F. Takasaki, H. Fujii, K. Satoh, H. Kodama, K. Hayashi, S. Odaka, S. Procureur, D. Attié, S. Bouteille, D. Calvet,C. Filosa, P. Magnier, I. Mandjavidze, M. Riallot, B. Marini, P. Gable, Y. Date, M. Sugiura, Y. Elshayeb, T. Elnady, M. Ezzy, E. Guerriero, V. Steiger, N. Serikoff, J.B. Mouret, B. Charlès,H. Helal, and M. Tayoubi (2017). Discovery of a big void in Khufu's pyramid by observation of cosmic-ray muons. Nature, 552(7685):386.

Moss, H., A. Vesga-Ramírez, V.A. Kudryavtsev, L. A. Núñez, and D. Sierra-Porta (2018). Muon tomography for the 


\section{Alejandra Vesga-Ramírez et al.}

Cerro Machín volcano. Technical report, Department of Physics \& Astronomy, University of Sheffield, Sheffield, United Kingdom.

Muñoz, E. (2017). Informe mensual de actividad de los volcanes Galeras, Cumbal, Chiles y Cerro Negro, Las Ánimas, Doña Juana y Azufral. Technical report, Reporte interno, Pasto, Colombia. INGEOMINAS.

Murcia, H.F., M.F. Sheridan, J.L. Macías, and G.P. Cortés (2010). Titan2d simulations of pyroclastic flows at Cerro Machín volcano, Colombia: Hazard implications. J. South Am. Earth Sci., 29(2):161-170.

Nagamine, K. (2003). Introductory muon science. Cambridge University Press.

Nishiyama, R., S. Miyamoto, and N. Naganawa (2014). Experimental study of source of background noise in muon radiography using emulsion film detectors. Geosci. Istrum. Methods Data Syst., 3(1):29-39.

Nishiyama, R., A. Taketa, S. Miyamoto, and K. Kasahara (2016). Monte Carlo simulation for back-ground study of geophysical inspection with cosmic-ray muons. Geophys. J. Int., 206(2):1039-1050.

Noli, P., F. Ambrosino, L. Bonechi, A. Bross, L. Cimmino, R. D’Alessandro, V. Masone, N. Mori,G. Passeggio, A. PlaDalmau, G. Saracino, E. Scarlini, and P. Strolin (2017). Muography of the Puy de Dôme. Ann. Geophys., 60(1):0105.

Okubo, S. and H.K.M. Tanaka (2012). Imaging the density profile of a volcano interior with cosmic-ray muon radiography combined with classical gravimetry. Measurement Science and Technology, 23(4):042001.

Oláh, L. and D. Varga (2017). Investigation of soft component in cosmic ray detection. Astroparticle Physics, 93:17-27

Olive, K. A., K. Agashe, C. Amsler, M. Antonelli, J. F. Arguin, D. M. Asner, H. Baer, H. R. Band, R. M. Barnett, T. Basaglia, C. W. Bauer, J. J. Beatty, V. L. Belousov, J. Beringer, G. Bernardi,S. Bethke, H. Bichsel, O. Biebel, E. Blucher, S. Blusk, G. Brooijmans, O. Buchmueller, V. Burkert,M. A. Bychkov, R. N. Cahn, M. Carena, A. Ceccucci, A. Cerri, D. Chakraborty, M. C. Chen,R. S. Chivukula, K. Copie, G. Cowan, O. Dahl, G. D’Ambrosio, T. Damour, D. De Florian,A. De Gouvéa, T. DeGrand, P. De Jong, G. Dissertori, B. A. Dobrescu, M. Doser, M. Drees,H. K. Dreiner, D. A. Edwards, S. Eidelman, J. Erler, V. V. Ezhela, W. Fetscher, Brian DavidFields, B. Foster, A. Freitas, T. K. Gaisser, H. Gallagher, L. Garren, H. J. Gerber, G. Gerbier,T. Gershon, T. Gherghetta, S. Golwala, M. Goodman, C. Grab, A. V. Gritsan, C. Grojean,D. E. Groom, M. Grünewald, A. Gurtu, T. Gutsche, H. E. Haber, K. Hagiwara, C. Hanhart,S. Hashimoto, Y. Hayato, K. G. Hayes, M. Heffner, B. Heltsley, J. J. Hernández-Rey, K. Hikasa,A. Höcker, J. Holder, A. Holtkamp, J. Huston, J. D. Jackson, K. F. Johnson, T. Junk, M. Kado,D. Karlen, U. F. Katz, S. R. Klein, E. Klempt, R. V. Kowalewski, F. Krauss, M. Kreps, B. Krusche,Yu V. Kuyanov, Y. Kwon, O. Lahav, J. Laiho, P. Langacker, A. Liddle, Z. Ligeti, C. J. Lin, T.M. Liss, L. Littenberg, K. S. Lugovsky, S. B. Lugovsky, F. Maltoni, T. Mannel, A. V. Manohar,W. J. Marciano, A. D. Martin, A. Masoni, J. Matthews, D. Milstead, P. Molaro, K. Mönig,F. Moortgat, M. J. Mortonson, H. Murayama, K. Nakamura, M. Narain, P. Nason, S. Navas,M. Neubert, P. Nevski, Y. Nir, L. Pape, J. Parsons, C. Patrignani, J. A. Peacock, M. Pennington,S. T. Petcov, A. Piepke, A. Pomarol, A. Quadt, S. Raby, J. Rademacker, G. Raffelt, B. N.Ratcliff, P. Richardson, A. Ringwald, S. Roesler, S. Rolli, A. Romaniouk, L. J. Rosenberg, J. L.Rosner, G. Rybka, C. T. Sachrajda, Y. Sakai, G. P. Salam, S. Sarkar, F. Sauli, O. Schneider,K. Scholberg, D. Scott, V. Sharma, S. R. Sharpe, M. Silari, T. Sjöstrand, P. Skands, J. G. Smith,G. F. Smoot, S. Spanier, H. Spieler, C. Spiering, A. Stahl, T. Stanev, S. L. Stone, T. Sumiyoshi,M. J. Syphers, F. Takahashi, M. Tanabashi, J. Terning, L. Tiator, M. Titov, N. P. Tkachenko,N. A. Törnqvist, D. Tovey, G. Valencia, G. Venanzoni, M. G. Vincter, P. Vogel, A. Vogt, S. P.Wakely, W. Walkowiak, C. W. Walter, D. R. Ward, G. Weiglein, D. H. Weinberg, E. J. Weinberg,M. White, L. R. Wiencke, C. G. Wohl, L. Wolfenstein, J. Womersley, C. L. Woody, R. L. Workman,A. Yamamoto, W. M. Yao, G. P. Zeller, O. V. Zenin, J. Zhang, R. Y. Zhu, F. Zimmermann, P. A.Zyla, G. Harper, V. S. Lugovsky, and P. Schaffner (2014). Review of particle physics. Chinese Physics C, 38(9), 8.

Ordón, M. I. and H. Cepeda (1997). Morphological changes of the active cone of Galeras volcano, Colombia, during the last century. J. Volcanol. Geotherm. Res., 77(1-4):71-87.

Ostapchenko, S. (2011). Monte Carlo treatment of hadronic interactions in enhanced pomeron scheme: Qgsjet-ii model. Phys. Rev. D, 83(1):014018.

Peña-Rodríguez, J., J. Pisco-Guabave, D. Sierra-Porta, M. Suárez-Durán, M. Arenas-Flórez, L. M. Pérez-Archila, J.D. Sanabria-Gómez, H. Asorey, and L. A. Núñez (2020). Design and construction of mute: a hybrid muon telescope. Journal of Instrumentation, 15(09) P09006.

Peña-Rodríguez, J., J. Pisco-Guabave, D. Sierra-Porta, M. Suárez-Durán, M. Arenas-Flórez, L. M. Pérez-Archila, J.D. Sanabria-Gómez, H. Asorey, and L. A. Núñez (2020). Design and construction of mute: a hybrid muon telescope. In preparation

Pesente, S., S. Vanini, M. Benettoni, G. Bonomi, P. Calvini, P. Checchia, E. Conti, F. Gonella, G. Nebbia, S. Squarcia, 


\section{Muon Tomography for Colombian volcanoes}

G. Viesti, A. Zenoni, and G. Zumerle (2009). First results on material identification and imaging with a largevolume muon tomography prototype. Nuclear Instruments and Methods in Physics Research Section A: Accelerators, Spectrometers, Detectors and Associated Equipment, 604(3):738-746.

Pierson, T.C., R.J. Janda, J.-C. Thouret, and C.A. Borrero (1990). Perturbation and melting of snow and ice by the 13 november 1985 eruption of Nevado del Ruiz, Colombia, and consequent mobilization, flow and deposition of lahars. Journal of Volcan.. Geothermal Res., 41(1-4):17-66.

Portal, A., P. Labazuy, J.-F. Lénat, S. Béné, P. Boivin, E. Busato, C. Cârloganu, C. Combaret,P. Dupieux, F. Fehr, P. Gay, I. Laktineh, D. Miallier, L. Mirabito, V. Niess, and B. Vulpescu (2013). Innerstructure of the Puy de Dôme volcano: cross-comparison of geophysical models (ert, gravimetry, muon imaging). Geoscientific Instrumentation Methods and Data Systems, 2:47-54

Rubio Sánchez, G. (1985). La erupción del 28-29 de marzo (1982) del volcán Chichonal un estudio breve de su tefra. Revista mexicana de ciencias geológicas, 6(1):48-56.

Rueda, H. (2005). Erupciones plinianas del holoceno en el volcán Cerro Machín, Colombia. estratigrafía, petrografía y dinámica eruptiva. Master's thesis, Universidad Nacional Autónoma de México, México.

Schultz, L. J., K.N. Borozdin, J. J. Gomez, G.E. Hogan, J. A. McGill, C.L. Morris, W.C. Priedhorsky, A. Saunders, and M.E. Teasdale (2004). Image reconstruction and material z discrimination via cosmic ray muon radiography. Nuclear Instruments and Methods in Physics Research Section A: Accelerators, Spectrometers, Detectors and Associated Equipment, 519(3):687-694.

Seidl, D., M. Hellweg, M. Calvache, D. Gómez, A. Ortega, R. Torres, F. Böker, B. Buttkus,E. Faber, and S. Greinwald (2003). The multiparameter station at Galeras volcano (Colombia): concept and realization. J. Volcanol. Geotherm. Res., 125(1-2):1-12.

Sennert, S.K. (2016). Global volcanism program 2016. Technical Report 10, Smithsonian Institution and US Geological Survey. Report on Nevado del Ruiz (Colombia), Weekly Volcanic Activity Report.

Suárez-Durán, M. (2015). Modulación de rayos cósmicos a nivel del suelo por cambios en el campo geomagnético, para la colaboración lago. Master thesis in physics, School of Physics, Universidad Industrial de Santander, Bucaramanga, Colombia.

Tanaka, H. K. M., and L. Oláh (2019). Overview of muographers. Philosophical Transactions of the Royal Society A: Mathematical, Phys. Engineering Sci., 377(2137):20180143.

Tanaka, H.K.M. (2013). Subsurface density mapping of the earth with cosmic ray muons. Nuclear Physics BProceedings Supplements, 243:239-248.

Tanaka, H.K.M. (2016). Visualization of the internal structure of volcanoes with cosmic-ray muons. Journal of the Physical Society of Japan, 85(9):091016.

Tanaka, H.K.M., T. Nakano, S. Takahashi, J. Yoshida, M. Takeo, J. Oikawa, T. Ohminato, Y. Aoki, E. Koyama, H. Tsuji, and K. Niwa (2007). High resolution imaging in the inhomogeneous crust with cosmic-ray muon radiography: The density structure below the volcanic crater floor of Mt. Asama, Japan. Earth Planet. Sci. Lett., 263(12):104-113.

Tapia, A., D. Dueñas, J. Rodríguez, J. Betancourt, and D.A Martínez-Caicedo (2016). First Monte Carlo simulation study of Galeras volcano structure using muon tomography. In Proceedings of Science, page 885.

Thompson, L. F., Stowell, J. P., Fargher, S. J., Steer, C. A., Loughney, K. L., O'Sullivan, E. M., ... \& Pidcock, R. J. (2020). The application of muon tomography to the imaging of railway tunnels, Phys. Rev. Res., 2.

Thouret, J.C., J.M. Cantagrel, R. Salinas, and A. Murcia (1990). Quaternary eruptive history of Nevado del Ruiz (Colombia). J. Volcanol. Geotherm. Res., 41(1-4):225-251.

Torres, D., D. Martínez, R. Torres, A. Tapia, J. Betancourt, J. Rodríguez, D. Dueñas, and D. Arturo (2019). Galeras volcano internal structure characterization using geological and geophysics techniques as input to muon tomography studies. In APS Meeting Abstracts, page Y05.002.

Tsyganenko, N. A. (2002). A model of the near magnetosphere with a dawn-dusk asymmetry 1. mathematical structure. J. Geophys. Res.: Space Physics, 107(A8): SMP 12-1-SMP12-15

Uchida, T., H. K.M. Tanaka, and M. Tanaka (2009). Space saving and power efficient readout system for cosmic-ray muon radiography. IEEE Trans. Nuclear Sci., 56(2):448-452.

Useche-Parra, J.S. and C.A. Avila-Bernal (2019). Estimation of cosmic-muon flux attenuation by mon-serrate hill in bogota. J. Instrumentation, 14(02):P02015.

Vásquez-Ramírez, A. (2019). Estimación de la respuesta generada por el detector MuTe al paso de partículas 


\section{Alejandra Vesga-Ramírez et al.}

cargadas. Master thesis in physics, School of Physics, Universidad Industrial de Santander, Bucaramanga, Colombia.

Vásquez-Ramírez, A., Suárez-Durán, M., Jaimes-Motta, A., Calderón-Ardila, R., Peña-Rodríguez, J., SánchezVillafrades, J., ... \& Núñez, L. A. (2020). Simulated response of MuTe, a hybrid Muon Telescope, Journal of Instrumentation, 15(08), P08004.

Valencia-Otero, M.L. (2017). Estudio de las componentes de secundarios en cascadas originadas por rayos cósmicos para aplicaciones sobre estructuras geológicas. Pregraduate research project, School of Physics, Universidad Industrial de Santander, Bucaramanga, Colombia.

Vesga-Ramírez, M.A. (2018). Inversión geofísica a partir de datos de muongrafía volcánica para proyecto mute. Master thesis in geophysics, School of Physics, Universidad Industrial de Santander, Bucaramanga, Colombia.

Zichichi, A., O. Barnabei, P. Pupillo, and F.R. Monaco (2000). Subnuclear Physics: The First 50 Years: Highlights from Erice to ELN, World scientific volume 24

*CORRESPONDING AUTHOR: David SIERRA-PORTA

Departamento de Física, Universidad de los Andes, Cra. 1 No. 18A-10 Edificio Ip, CP 111711 